\title{
Article
}

\section{Varieties of childhood maltreatment as predictors of adult paranormality and New Age Orientation}

Rogers, Paul and Lowrie, Emma Louise

Available at http://clok.uclan.ac.uk/19877/

Rogers, Paul and Lowrie, Emma Louise (2016) Varieties of childhood maltreatment as predictors of adult paranormality and New Age Orientation. Personality and Individual Differences, 92 . pp. 37-45. ISSN 0191-8869

It is advisable to refer to the publisher's version if you intend to cite from the work. http://dx.doi.org/10.1016/j.paid.2015.12.019

For more information about UCLan's research in this area go to http://www.uclan.ac.uk/researchgroups/ and search for < name of research Group>.

For information about Research generally at UCLan please go to http://www.uclan.ac.uk/research/

All outputs in CLoK are protected by Intellectual Property Rights law, including Copyright law. Copyright, IPR and Moral Rights for the works on this site are retained by the individual authors and/or other copyright owners. Terms and conditions for use of this material are defined in the policies page. 
Elsevier Editorial System(tm) for

Personality and Individual Differences

Manuscript Draft

Manuscript Number: PAID-D-15-00819R1

Title: Varieties of childhood maltreatment as predictors of adult paranormality and New Age Orientation

Article Type: Full Length Article

Section/Category: Research Paper ( $<5000$ words)

Keywords: PARANORMAL, NEW AGE; FANTASY; MALTREATMENT; ABUSE; PARENTIFICATION; THREAT

Corresponding Author: Dr. Paul Rogers, Ph.D.

Corresponding Author's Institution: Goldsmith's College, University of London

First Author: Paul Rogers, Ph.D.

Order of Authors: Paul Rogers, Ph.D.; Emma L Lowrie, BSc.

Abstract: This study examines the degree to which varieties of childhood maltreatment (in)directly predict adult paranormal and New Age worldviews. Mediation analyses were performed with maltreatment types serving as potential predictors, facets of fantasy proneness as potential mediators and aspects of adult paranormality (anomalous experiences, beliefs, abilities and fears) plus a general New Age orientation as five separate criteria measures. Several hypotheses were (partially) supported. First, child sexual abuse directly predicted more selfreported anomalous experiences, with parental threats of rejection directly predicting fewer anomalous fears in adulthood. Second, indirect relationships between childhood neglect, sexual abuse, emotional abuse and instrumental parentification emerged for all criteria except anomalous fears, with these relationships mediated by at least one facet of fantasy proneness; either vivid/realistic and/or make-believe fantasizing. These findings are consistent with Irwin's (2009) Psychodynamic Functions Hypothesis; the notion that adult paranormality offers an adaptive, needs-serving mechanism for coping with sense of diminished control often stemming from childhood trauma. Contrary to Irwin's model, childhood physical abuse, emotional parentification and parental threats of both abandonment and punishment failed to predict any outcome measure either directly or via more pronounced fantasizing. Theoretical implications, methodological issues and ideas for future research are discussed. 
F.A.O. Dr Tony Vernon

Editor-in-Chief, Personality \& Individual Differences

Department of Psychology

Western University

London

Ontario

Canada N6A 5C2

02 December 2015
Department of Psychology

Herbert James Building

University of Winchester

Sparkford Road,

Winchester

Hampshire SO22 4NR, UK

T: (07837) 193372

E: progers1966@gmail.com

\section{RE: Manuscript for Re-Submission to PAID (Ref. PAID-D-15-00819)}

\section{Dear Dr Vernon,}

Please find enclosed a revised copy of our paper "Varieties of childhood maltreatment as predictors of adult paranormality " (co-authored with Emma Lowrie) for re-submission to Personality \& Individual Differences (PAID). Having received comments from three anonymous reviewers the following changes have now been made:

\section{Major Changes}

Page(s) Line(s) Change

03 01-17 A more detailed account of the PFH, including discussion of the theoretical role fantasy proneness plays, is added to the INTRODUCTION(cf. Reviewer 2).

$07 \quad$ 01-12 Rationale for exploring specific facets of fantasy proneness is added (cf. Reviewer 2).

01-07 -- $\quad$ The above additions contrast with other feedback that the INTRODUCTION is too long (cf. Reviewer 1). In attempt to satisfy these conflicting viewpoints, the INTROCTION has been restructured and re-written for greater succinctness wherever possible.

11-14 11-09 The mediation analysis subsection within RESULTS has been restructured for greater clarity and reduced "long-windedness" (cf. Reviewer 1).

14-18 10-22 DISCUSSION is now better aligned to RESULTS, with the mixed nature of current findings highlighted (cf. Reviewer 3).

14-18 10-22 DISCUSSION is now less speculative. (cf. Reviewer 3).

18-21 23-05 Comment on the theoretical implications of current findings has been enhanced (cf. Reviewer 1). This is now included as a separate sub-section of the DISCUSSION.

21-22 21-02 Comment on problem of potential bi-directionality has been added (cf. Reviewer 2).

21-22 21-02 Ideas for future research are more consistent with methodological limitations (cf. Reviewer 1).

22 07-21 GENERAL CONCLUSION is now less speculative (cf. Reviewer 3).

Tables -- $\quad$ For cross-table consistency, the contents of Table 1 has been re-ordered with criteria measures at the top followed by mediators, predictors and finally demographics. Also for cross-table consistency, alternate rows in Table 1 are also now shaded

Tables -- $\quad$ To further reduce complexity and "long-windedness" Confidence Interval $(C I)$ data has been omitted from the RESULTS section text and included in a new table, namely Table 3 (cf. Reviewer 1). Remaining tables (not for review) have been re-numbered accordingly. 


\begin{tabular}{|c|c|c|}
\hline $\operatorname{Page}(\mathrm{s})$ & Line(s) & Change \\
\hline Abstract & -- & $\begin{array}{l}\text { Extent to which findings are consistent with Irwin's (2009) PFH has been rephrased (cf. Reviewer } \\
\text { 3). }\end{array}$ \\
\hline 03 & $01-05$ & Meaning of the term "psychodynamic" within Irwin's (2009) PFH is clarified (cf. Reviewer 3). \\
\hline 08 & $11-14$ & $\begin{array}{l}\text { Details of initial sample size and response rate is added (cf. Reviewer 1). Reference to the sample } \\
\text { size being "large" and "representativeness" is deleted (cf. Reviewer 2; Reviewer } 3 \text { ). }\end{array}$ \\
\hline 09 & 24 & Details of data collection period is added (cf. Reviewer 1). \\
\hline 10 & -- & Details of item deletion are now provided (cf. Reviewer 3 ). \\
\hline 10 & -- & Rate of missing values for each measure is now reported (cf. Reviewer 3 ). \\
\hline 10 & -- & Justification of variable dichotomization is added (cf. Reviewer 2). \\
\hline 22 & $07-21$ & Final conclusion is now less speculative (cf. Reviewer 3 ). \\
\hline Footnotes & -- & A number of footnotes have been re-integrated into the main text else omitted (cf. PAID guidelines) \\
\hline Tables & -- & $\begin{array}{l}\text { The visual structure of Table } 2 \text { has been improved not through use of boldface (cf. Reviewer } 1) \\
\text { but through simplification and use of blank rows. Tables } 4 \text { to } 8 \text { were not amended as boldface would } \\
\text { have necessitated an even smaller font size. }\end{array}$ \\
\hline Figures & -- & For greater printing clarity shaded (grey) path lines are replaced by unshaded (black) path lines. \\
\hline All & -- & More references have been added as appropriate (cf. Reviewer 1). \\
\hline All & -- & Citation errors have been amended whenever found (cf. Reviewer 1). \\
\hline All & -- & The manuscript has been re-edited with any spelling and/or grammatical errors rectified. \\
\hline All & -- & Sub-headings are now numbered and italicised (cf. PAID guidelines) \\
\hline
\end{tabular}

For the record, we have complied with British Psychological Society (BPS) ethical guidelines, have no conflict of interests and had adhered to the latest APA style guidelines. DOI numbers are supplied wherever available. Finally, the manuscript is 4.992 words (including footnotes and bibliography, but excluding title page and abstract) with three tables and five figures. Also submitted as supplementary material for reviewers' only are five additional tables of mediation data. We trust this supplementary information will be helpful and look forward to receiving further feedback.

Yours Sincerely,

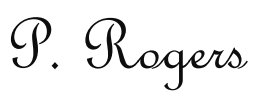

Dr Paul Rogers

Senior Lecturer

Department of Psychology

University of Winchester 


\section{*Response to reviewers - WITHOUT author identities}

Address as per cover letter

F.A.O. Dr Tony Vernon

Editor-in-Chief, Personality \& Individual Differences

Department of Psychology

Western University

London

Ontario

Canada N6A 5C2

02 December 2015

\section{RE: Manuscript for Re-Submission to PAID (Ref. PAID-D-15-00819)}

Dear Dr Vernon,

Please find enclosed a revised copy of our paper "Varieties of childhood maltreatment as predictors of adult paranormality " (co-authored with Emma Lowrie) for re-submission to Personality \& Individual Differences (PAID). Having received comments from three anonymous reviewers the following changes have now been made:

\section{Major Changes}

Page(s) Line(s) Change

03 01-17 A more detailed account of the PFH, including discussion of the theoretical role fantasy proneness plays, is added to the INTRODUCTION(cf. Reviewer 2).

$07 \quad$ 01-12 Rationale for exploring specific facets of fantasy proneness is added (cf. Reviewer 2).

01-07 -- $\quad$ The above additions contrast with other feedback that the INTRODUCTION is too long (cf Reviewer 1). In attempt to satisfy these conflicting viewpoints, the INTROCTION has been restructured and re-written for greater succinctness wherever possible.

11-14 11-09 The mediation analysis subsection within RESULTS has been restructured for greater clarity and reduced "long-windedness" (cf. Reviewer 1).

14-18 10-22 DISCUSSION is now better aligned to RESULTS, with the mixed nature of current findings highlighted (cf. Reviewer 3).

14-18 10-22 DISCUSSION is now less speculative. (cf. Reviewer 3).

18-21 23-05 Comment on the theoretical implications of current findings has been enhanced (cf. Reviewer 1). This is now included as a separate sub-section of the DISCUSSION.

21-22 21-02 Comment on problem of potential bi-directionality has been added (cf. Reviewer 2).

21-22 21-02 Ideas for future research are more consistent with methodological limitations (cf. Reviewer 1).

22 07-21 GENERAL CONCLUSION is now less speculative (cf. Reviewer 3).

Tables -- $\quad$ For cross-table consistency, the contents of Table 1 has been re-ordered with criteria measures at the top followed by mediators, predictors and finally demographics. Also for cross-table consistency, alternate rows in Table 1 are also now shaded

Tables -- $\quad$ To further reduce complexity and "long-windedness" Confidence Interval $(C I)$ data has been omitted from the RESULTS section text and included in a new table, namely Table 3 (cf. Reviewer 1). Remaining tables (not for review) have been re-numbered accordingly. 


\begin{tabular}{|c|c|c|}
\hline $\operatorname{Page}(\mathrm{s})$ & Line(s) & Change \\
\hline Abstract & -- & $\begin{array}{l}\text { Extent to which findings are consistent with Irwin's (2009) PFH has been rephrased (cf. Reviewer } \\
\text { 3). }\end{array}$ \\
\hline 03 & $01-05$ & Meaning of the term "psychodynamic" within Irwin's (2009) PFH is clarified (cf. Reviewer 3). \\
\hline 08 & $11-14$ & $\begin{array}{l}\text { Details of initial sample size and response rate is added (cf. Reviewer 1). Reference to the sample } \\
\text { size being "large" and "representativeness" is deleted (cf. Reviewer 2; Reviewer } 3 \text { ). }\end{array}$ \\
\hline 09 & 24 & Details of data collection period is added (cf. Reviewer 1). \\
\hline 10 & -- & Details of item deletion are now provided (cf. Reviewer 3 ). \\
\hline 10 & -- & Rate of missing values for each measure is now reported (cf. Reviewer 3 ). \\
\hline 10 & -- & Justification of variable dichotomization is added (cf. Reviewer 2). \\
\hline 22 & $07-21$ & Final conclusion is now less speculative (cf. Reviewer 3 ). \\
\hline Footnotes & -- & A number of footnotes have been re-integrated into the main text else omitted (cf. PAID guidelines) \\
\hline Tables & -- & $\begin{array}{l}\text { The visual structure of Table } 2 \text { has been improved not through use of boldface (cf. Reviewer } 1 \text { ) } \\
\text { but through simplification and use of blank rows. Tables } 4 \text { to } 8 \text { were not amended as boldface would } \\
\text { have necessitated an even smaller font size. }\end{array}$ \\
\hline Figures & -- & For greater printing clarity shaded (grey) path lines are replaced by unshaded (black) path lines. \\
\hline All & -- & More references have been added as appropriate (cf. Reviewer 1). \\
\hline All & -- & Citation errors have been amended whenever found (cf. Reviewer 1). \\
\hline All & -- & The manuscript has been re-edited with any spelling and/or grammatical errors rectified. \\
\hline All & -- & Sub-headings are now numbered and italicised (cf. PAID guidelines) \\
\hline
\end{tabular}

For the record, we have complied with British Psychological Society (BPS) ethical guidelines, have no conflict of interests and had adhered to the latest APA style guidelines. DOI numbers are supplied wherever available. Finally, the manuscript is 4.992 words (including footnotes and bibliography, but excluding title page and abstract) with three tables and five figures. Also submitted as supplementary material for reviewers' only are five additional tables of mediation data. We trust this supplementary information will be helpful and look forward to receiving further feedback.

Yours Sincerely,

Qnnon. 
Varieties of childhood maltreatment as predictors of adult paranormality and New Age Orientation

\author{
Paul Rogers PhD. \\ Anomalistic Psychology Research Unit \\ Department of Psychology \\ Goldsmith's College, University of London \\ $\&$ \\ Emma Lowrie BSc. \\ School of Psychology \\ University of Central Lancashire
}

Dr Paul Rogers is now at the University of Winchester. Please address correspondence to:

Dr Paul Rogers, Department of Psychology, Herbert James Building, University of Winchester, Sparkford Road, Winchester, Hampshire SO22 4NR, UK. Tel: +44 (0)1962 82 7098. Email: progers1966@ gmail.com 
Varieties of childhood maltreatment as predictors of adult paranormality and New Age Orientation

\section{Highlights}

1. Child sexual abuse directly predicted more self-reported anomalous experiences, with parental threats of rejection directly predicting fewer anomalous fears in adulthood.

2. Indirect relationships between childhood neglect, sexual abuse, emotional abuse and instrumental parentification emerged for anomalous experiences, beliefs, selfproclaimed abilities plus general New Age orientation.

3. These relationships were mediated by at least one facet of fantasy proneness; either vivid/realistic and/or make-believe fantasizing.

4. Contrary to expectation, childhood physical abuse, emotional parentification and parental threats of both abandonment and punishment failed to predict any outcome measure either directly or via more pronounced fantasizing.

5. Current findings are consistent with Irwin's (2009) Psychodynamic Functions Hypothesis; the notion that adult paranormality offers an adaptive, needs-serving mechanism for coping with sense of diminished control often stemming from childhood trauma. 
Varieties of childhood maltreatment as predictors of adult paranormality and New Age Orientation 


\begin{abstract}
This study examines the degree to which varieties of childhood maltreatment (in)directly predict adult paranormal and New Age worldviews. Mediation analyses were performed with maltreatment types serving as potential predictors, facets of fantasy proneness as potential mediators and aspects of adult paranormality (anomalous experiences, beliefs, abilities and fears) plus a general New Age orientation as five separate criteria measures. Several hypotheses were (partially) supported. First, child sexual abuse directly predicted more self-reported anomalous experiences, with parental threats of rejection directly predicting fewer anomalous fears in adulthood. Second, indirect relationships between childhood neglect, sexual abuse, emotional abuse and instrumental parentification emerged for all criteria except anomalous fears, with these relationships mediated by at least one facet of fantasy proneness; either vivid/realistic and/or make-believe fantasizing. These findings are consistent with Irwin's (2009) Psychodynamic Functions Hypothesis; the notion that adult paranormality offers an adaptive, needs-serving mechanism for coping with sense of diminished control often stemming from childhood trauma. Contrary to Irwin's model, childhood physical abuse, emotional parentification and parental threats of both abandonment and punishment failed to predict any outcome measure either directly or via more pronounced fantasizing. Theoretical implications, methodological issues and ideas for future research are discussed.
\end{abstract}

Keywords: PARANORMAL, NEW AGE; FANTASY; MALTREATMENT; ABUSE; PARENTIFICATION; THREAT 


\section{Introduction}

According to Irwin's (2009) Psychodynamic Functions Hypothesis (PFH) scientifically

unaccepted beliefs (SUBs) ${ }^{1}$ develop as a means of coping with a diminished sense of control often stemming from childhood trauma. Endorsement of, say, extrasensory perception engenders an illusory sense of control over people, objects and/or events. Such beliefs are seen as an unconsciously motivated, needs-serving, adaptive mechanism for alleviating feelings of vulnerability. Similar claims have been made about a general New Age orientation (Granqvist \& Hagekull, 2001).

There is reasonable support for Irwin's PFH with self-reported paranormal experiences and/or beliefs linked to global measures of childhood trauma (e.g., Rogers, Qualter \& Phelps, 2007) as well as intrafamilial physical abuse (Irwin, 1992; Lawrence, Edwards, Barraclough \& Church, 1995; Perkins \& Allen, 2006), sexual abuse (Berkowski \& MacDonald, 2014; Ross \& Joshi, 1992), emotional abuse (Berkowski \& MacDonald, 2014; Rabeyron \& Watt, 2010), being raised by alcoholic (Irwin, 1994) or overly-authoritarian (Watt, Watson, \& Wilson, 2007) parents and domestic instability (Lawrence et al., 1995).

Evidence for the PFH is however mixed. Lawrence et al. (1995) found no relationship between child sexual abuse and adult paranormal belief or experiences. Berkowski and MacDonald (2014) report a similar a lack of correlation between physical abuse and all seven dimensions of Tobacyk's (2004) Revised Paranormal Belief Scale. Thus, the extent to which varieties of childhood trauma are associated with adult paranormality remains unclear. Other types of child maltreatment such as parentification and parental threats also need testing within the PFH framework. The present study addresses these issues.

\subsection{Parentification}


Parentification represents a role-reversal in the child-parent relationship of which two types exist. Instrumental parentification manifests as the child taking care of everyday household duties (e.g., cooking, cleaning) as an adaptive response to temporary parental absence or incapacity. In contrast, emotional parentification manifests as the child being coerced or manipulated into being responsible for the physical, psychosocial and emotional well-being of his/her parent(s), sibling(s) or family dynamics (e.g., being peace-maker in times of family crisis). Only emotional parentification is harmful to children (Hooper, 2007).

Emotional parentification is not uncommon and has its own unique aetiology and noticeably, encompasses three of the four defining characteristics of trauma, namely a perceived loss of control, feelings of being overwhelmed and long-term negative consequences. Whilst not always unexpected (the fourth defining characteristic of trauma) parentification can occur following, say, the sudden death of a parent (Byng-Hall, 2008; Hooper, 2007). Given Irwin's PFH it would be reasonable to expect emotional (but not instrumental) parentification to predict SUBs. Consistent with this view is evidence that New Age followers reported more child-parent role-reversal than non-New Agers (Granqvist, Ivarsson, Broberg \& Hagekull, 2007).

\subsection{Parental Threat}

By undermining a child's sense of domestic security parental threat is another potential predictor of adult paranormality. Indirect support for this claim comes from evidence that New-Agers also report more parental rejection (Granqvist et al., 2007) with paranormal believers having more authoritarian parents (Watt, Watson \& Wilson, 2007).

\subsection{Fantasy Proneness}


Several studies suggest fantasy proneness is a key mediating variable in the childhood trauma-adult paranormality relationship (e.g., Berkowski \& MacDonald, 2014; Lawrence et al., 1995; Rogers et al., 2007). In line with the PFH it seems prolonged and/or excessive fantasizing is employed as a way of distracting from (avoidantly coping with) the aftermath of childhood maltreatment.

To date, no studies have examined the extent to which different facets of fantasy proneness serve as mediators in the PFH. Instead commonly used measures of fantasy such as the Creative Experiences Questionnaire (CEQ: Merckelbach, Horselenberg \& Muris, 2001) are treated as unidimensional (e.g., Berkowski \& MacDonald, 2014; Rogers et al., 2007). According to Sánchez-Bernardos and Avia (2004) the CEQ comprises three distinct dimensions namely (a) vivid/realistic, (b) escapist and (c) make-believe fantasizing. Given previous links between paranormal belief and avoidant coping (Callaghan \& Irwin, 2003; Rogers Qualter, Phelps \& Gardner, 2006) it is reasonable to expect escapist fantasizing to be the strongest predictor of SUBs. However, given the content of the three CEQ subscales vivid/realistic and make-believe fantasizing seem more applicable to the $\mathrm{PFH}^{2}$.

\subsection{Study Overview \& Hypotheses}

The current study extends previous work by examining the extent to which recalled experiences of childhood maltreatment (i.e. parental neglect, physical, sexual and emotional abuse, parentification and threats of rejection, abandonment and punishment) predict SUBs (i.e. reported anomalous experiences, beliefs, abilities and fears plus a general New Age orientation). In line with Irwin's PFH, the extent to which these predictive relationships are mediated by separate facets of fantasy proneness (i.e. vivid/realistic, escapist and makebelieve fantasizing) is also investigated. The following general hypotheses are forwarded. 
H1: all forms of childhood maltreatment will be direct predictors of more pronounced SUBs (all aspects).

H2: more severe forms of child maltreatment (e.g., emotional over instrumental parentification; abusive acts rather than threats) will be stronger predictors of SUBs than arguably "lesser" forms of maltreatment.

H3: all forms of childhood maltreatment will predict stronger SUBs indirectly via the mediating impact of heightened fantasy proneness.

H4: vivid/realistic and make-believe fantasizing will be stronger mediators of all predictorcriteria relationships than will escapist fantasizing.

\section{Method}

\subsection{Participants}

Of 250 individuals sampled 226 returned usable questionnaires, a response rate of $90.4 \%$. The sample had an equal gender split (50.9\% female) with respondents aged 19 to 92 years ( $M=39.0$ years; $S D=16.3$ years). Most were of Caucasian ethnicity $(82.4 \%)$ and either employed (55.8\%), in full-time education $(18.0 \%)$ or retired $(12.9 \%)$. Around a quarter were qualified to at least undergraduate degree or equivalent (22.2\%).

\subsection{Materials}

The following psychometrically sound measures were included in the order presented here or, for counterbalancing purposes, in reversed order (except for demographics). All (sub)scales were rated from 1 'never/strongly disagree' to 5 'always/strongly agree'.

The Child Abuse \& Trauma Scale (CATS: Kent \& Waller, 1998) is a 38 item scale assessing recalled experiences of parental neglect plus physical, sexual and emotional abuse in childhood. 
The Parental Threat Inventory-Revised (PTI-R: Scher, Stein, Ingram, Malcarne \& McQuaid, 2002) is a 17 item retrospective measure of maternal/paternal threats of rejection, abandonment and physical punishment. For cross-measure comparability maternal and paternal scores were combined to form three "parental" threat subscales.

The Parentification Questionnaire (PQ: Hooper \& Wallace, 2009) is a 21 item retrospective measure assessing emotional and instrumental parentification plus the perceived fairness of parentification in childhood.

Fantasy Proneness. Fantasy proneness was examined via the Creative Experiences Questionnaire (CEQ: Merckelbach et al, 2001), a 25 item measure of vivid/realistic, escapist and make-believe fantasising (Sánchez-Bernardos \& Avia, 2004). Four CEQ items that referenced paranormal or religious phenomena were removed to avoid cross-scale contamination.

.Adult Paranormality: Adult paranormality was examined via the Anomalous Experiences Inventory (AEI: Gallagher, Kumar \& Pekula, 1994), a 63 item measure assessing reported experiences of, belief in, claimed abilities for and fears about various paranormal phenomena. A fifth AEI subscale exploring drug and alcohol use was omitted.

New Age Orientation: This was investigated using the New Age Orientation Scale (NAOS: Granqvist \& Hagekull, 2001), a 22 item unidimensional measure of people's endorsement of various New Age concepts as outlined in footnote 1.

Demographics: Finally, respondents indicated their gender, age, ethnicity (16 categories), occupational status (12 categories) and general level of qualification (from 1 'none' to 5 'postgraduate degree/professional').

\subsection{Procedure}


Members if the UK public were recruited opportunistically from businesses (e.g. corporate coffee shops) in various towns/cities (e.g., Accrington, Blackburn, Preston) within NorthWest England during the Autumn of 2013. Volunteers were handed a questionnaire and asked to answer all questions as quickly and honestly as possible without conferring. No time limit or financial incentives were given. A detachable debrief sheet was supplied with completed questionnaires handed back to the researcher else returned via the post. British Psychological Society (BPS) ethical guidelines were adhered to.

\section{Results}

\subsection{Preliminary Analyses}

Most measures had an acceptable level of internal reliability with item deletion ${ }^{3}$ used to improve initially low internal reliabilities to the levels shown in Table 1. The rate of missing values across the various criteria, mediators and predictors was acceptably low (all $\leq 7.1 \%$ ). Mean (sub)scale ratings were computed with missing values replaced via mean substitution ${ }^{4}$. $* * *$ Table 1 here $* * *$

Whilst several subscales had a non-normal distribution, histograms confirmed all but four were suitable for parametric analysis. These four were subsequently dichotomised into some (yes) verses none (no) maltreatment ${ }^{5}$. Following dichotomization 70 (32.1\% of) respondents reported experiencing child sexual abuse with $116(54.0 \%), 94(44.1 \%)$ and $135(63.1 \%)$ reporting exposure to parental threats of rejection, abandonment and physical punishment respectively.

\subsection{Correlations}

Unsurprisingly, the five SUB criteria were highly inter-correlated $(r ' s \leq .29 ; p$ ' $s<.001)$. As Table 2 shows, these also correlated positively with the three fantasy mediators which, in 
turn, were also inter-correlated. Five childhood maltreatment measures - neglect, sexual abuse (yes/no), emotional abuse, instrumental parentification and parental threats of rejection (yes/no) - correlated with at least one SUB and hence were deemed viable as potential predictors. Likewise, all three fantasy subscales were viable as potential mediators. No evidence of predictor multicollinearity was found ( $r$ 's $\leq .85$; Tabachnik \& Fidell, 2007). Finally, respondent gender correlated with both anomalous fears, $r_{\mathrm{b}}=.13 ; p=.017$, and New Age orientation, $r_{\mathrm{b}}=.14 ; p=.048$, with respondent age correlating negatively with anomalous beliefs, $r=-.16 ; p=.023$.

$$
* * * \text { Table } 2 \text { here } * * *
$$

\subsection{Mediation Analyses}

Mediation analysis tested the extent to which each facet of fantasy proneness causally linked the various child maltreatment predictors to each type of SUB (cf. Irwin, 2009) and thus was deemed suitable for current purposes.

Five mediation analyses (with 5,000 bias-corrected bootstrapped sampling) were performed using INDIRECT for SPSS (Hayes, 2013b; c). For consistency, the same potential covariates, predictors, and mediators (outlined above) were entered into all models except anomalous fears which, by comparison, contained just one predictor; parental threats of rejection. Fantasy subscales were entered in parallel resulting in single-step, multiple mediator models (Hayes, 2013). Finally, respondent gender and age were entered as potential covariates $^{6}$.

All models were highly significant (see Figures 1 to 5) with four of the five models accounting for $20-30 \%$ of criteria variance (adjusted $R^{2}=16$ to $27 \%$ ). The exception was the single-predictor model for anomalous fears which explained just $10 \%$ of criterion variance (adjusted $\left.R^{2}=7 \%\right)$.

\footnotetext{
*** Figures 1 to 5 here $* * *$
} 
Total Direct Effects: Initial Predictor-to-Criteria Relationships: Child sexual abuse was a significant, direct and positive predictor of all criteria except anomalous fears (beta's from .26 to $.42 ; p$ 's $<.05$ ). Similarly, emotional abuse was a (near) significant, positive predictor of anomalous experiences, anomalous beliefs and New Age orientation (beta's from .10 to .13; $p$ 's $\leq .066$ ). Both neglect and instrumental parentification were (marginal) predictors of New Age orientation ( $b e t a=.13 ; p=.053$ and $b e t a=.15 ; p=.035$ respectively) with parental threats of rejection a significant negative predictor of anomalous fears (beta=-.29; $p=.012$ ).

Predictor-to-Mediator Relationships: As Figures 1 to 5 also show, childhood neglect was a positive predictor of all fantasy mediators in all models except that for anomalous fears. The same was true for two other predictors, namely sexual and emotional abuse. By comparison, instrumental parentification was positively associated with vivid/realistic and make-believe, but not escapist, fantasizing. The pattern for anomalous fears was somewhat different with the one included predictor - parental rejection - not linked to any fantasy mediator.

Mediator-to-Criteria Relationships: Vivid/realistic fantasizing was a positive predictor of anomalous experiences, beliefs, abilities and New Age orientation. In contrast, escapist fantasizing was not related to any criteria. Finally, make-believe fantasizing was a positive predictor of both anomalous beliefs and New Age orientation.

Indirect Effects: The Mediating Impact of Fantasy Proneness: Table 3 presents mediator $(a b)$ path coefficients ${ }^{7}$ plus lower and upper $95 \%$ bootstrapped confidence intervals (CIs) for each model. CIs that do not cross zero indicate a significant mediation effect (Hayes, 2013a).

As Table 3 shows, vivid/realistic fantasizing had a significant mediating impact on the relationship between all four predictors and three criteria, the latter being anomalous experiences, anomalous abilities and New Age orientation. Vivid/realistic fantasizing also mediated the relationship between two predictors - childhood neglect and emotional abuse - 
and anomalous beliefs. As already implied, escapist fantasizing had no significant mediating impact on any predictor-criteria relationship. Finally, make-believe fantasizing mediated the relationship between all four predictors and both anomalous and New Age beliefs.

Net Direct Effects: Final Predictor-to-Criteria Relationships: With all indirect (mediator) effects accounted for, the net direct effect of just two predictors remained significant. First, child sexual abuse was a direct, positive predictor of anomalous experiences ( beta=.31; $p=.007)$. Second, parental threats of rejection was a direct, negative predictor of anomalous fears $($ beta $=.31 ; p=.007)$.

\subsection{Facets of Fantasy Proneness}

Table 3 shows that, when significant, vivid/realistic fantasizing had similar mediating impact in causally linking childhood neglect, emotional abuse and instrumental parentification to all criteria except anomalous fears ( $a b$ coefficients from .04 to .06). Interestingly, vivid/realistic fantasizing had much stronger impact on linking child sexual abuse to three of these criteria ( $a b$ coefficients from .14 to .15).

Similar trends existed for make-believe fantasizing with this having a comparable mediating impact on linking neglect, emotional abuse and instrumental parentification predictors to associated SUBs ( $a b$ coefficients from .04 to .07). Relative to these, makebelieve fantasizing had much stronger impact linking child sexual abuse to anomalous abilities and New Age orientation ( $a b$ coefficients equal of .17 and .11 respectively).

\section{Discussion}

Overall, partial support for hypotheses was found with several varieties of child maltreatment predicting adult SUBs either directly else indirectly through heightened fantasy proneness. These findings are now discussed. 


\subsection{Net Direct Effects: Predictors of Adult Paranormality \& New Age Orientation.}

Adult survivors of child sexual abuse reported more anomalous experiences than adults who had not been sexual abused as children. These data support previous studies linking child sexual assault to adult paranormality (Berkowski, \& MacDonald, 2014; Ross \& Joshi, 1992) with current evidence implying the relationship is directly causal (cf. Irwin, 2009).

Similarly, adults exposed to parental threats of rejection were less fearful of anomalous events such as visiting a psychic or using a Ouija board (Gallagher et al., 1994) than those who had not received such threats. These data are consistent with claims that New Agers followers experience more frequent rejection threats (Granqvist et al., 2007).

Contrary to expectations, individuals who suffered childhood neglect, physical abuse, emotional abuse, emotional parentification and parental threats of either abandonment or punishment were just as likely to maintain SUBs as their non-abused counterparts. Thus, current data fail to support previous claims of a direct link between these types of maltreatment and paranormal/New Age worldviews (e.g., Perkins \& Allen, 2006). In sum, some support for $\mathrm{H} 1$ was found although this was limited to just two child maltreatment predictors.

Surprisingly, child sexual abuse and rejection threats had similarly sized path coefficients implying there is little difference in their strength as direct predictors of adult SUBs. With anomalous experiences and fears having just one direct predictor each $\mathrm{H} 2$ could not be tested.

\subsection{Indirect Effects: The Mediating Impact of Fantasy Proneness}

As expected a number of indirect relationships via the mediating impact of heightened fantasy proneness were found. First, survivors of child sexual abuse reported more anomalous experiences, beliefs and abilities (marginally) plus a stronger New Age orientation if they 
were also prone to more vivid/realistic fantasising. The same individuals also maintained stronger anomalous and New Age beliefs if they were prone to more make-believe fantasising. Second, adults exposed to childhood neglect reported more anomalous experiences, beliefs, abilities and a stronger New Age orientation if they engaged in more make-believe fantasising. Third, identical trends existed for adult survivors of childhood emotional abuse. Thus, current findings are consistent with evidence linking all three types of childhood maltreatment to adult paranormality (e.g., Berkowski, \& MacDonald, 2014; Irwin, 1994; Rabeyron \& Watt, 2010; Ross \& Joshi, 1992). In doing so, they provide further support for Irwin's PFH.

Surprisingly, childhood physical abuse was not related - either directly or indirectly - to adult SUBs. Whilst consistent with some research (Berkowski, \& MacDonald, 2014) current trends contradict most other examinations of the PFH (Irwin, 1992; Lawrence et al., 1995; Perkins \& Allen, 2006). It is possible such differences reflect the type of physical abuse assessed here (i.e., non-specific physical punishment for rule-breaking) verses elsewhere (e.g., punching, kicking; Perkins \& Allen, 2006) with only more extreme physical abuse predicting endorsement of paranormal/New Age worldviews. Given the low internal reliability of the CATS physical abuse subscale employed here, further research seems warranted.

Also contrary to expectations, emotional parentification had neither a direct nor indirect relationship with any SUB. Parallel non-significant trends were also found for perceptions of parentification fairness. By comparison, adults who experienced instrumental parentification as children reported more pronounced anomalous experiences, beliefs, abilities and New Age orientation if they also engaged in more vivid/realistic and/or make-believe fantasising. This was surprising given the aforementioned lack of association with emotional parentification. Paradoxically, it is the less damaging instrumental parentification - where the child 
undertakes everyday household chores in an adaptive response to the temporary absence or incapacity of one parent (Hooper, 2007) - that is indirectly linked to adult endorsement of paranormal and New Age concepts. Current findings are thus at odds with those reported by Granqvist et al. (2007) who found New Age orientation was associated with more [emotional] parentification.

Finally, parental threats of rejection, abandonment and physical punishment were, for the most part, not factors in shaping SUBs. That said, adults who as children endured parental threats of rejection did report fewer anomalous fears (as discussed above). The implication here is that arguably "lesser" forms of child maltreatment - for instance threats of rather than acts of physical abuse (Scher et al., 2002) - also play a role SUB formation (cf. Irwin, 2009). This singular finding, coupled with the dichotomization of the PTI-R rejection threats subscale, suggest more research is needed to verify current trends.

To summarize, childhood neglect, sexual abuse, emotional abuse and instrumental parentification were all indirectly predictive of adult paranormal and New Age worldviews via the mediating effect of (at least one facet of) fantasy proneness. As such, some support for H3 emerged, albeit across just four of the original ten child maltreatment predictors.

\subsection{Facets of Fantasy Proneness}

Adult survivors of child maltreatment were more inclined to endorse SUBs if they are prone to vivid/realistic fantasies which cannot be distinguished from real memories and/or to fantasising about fictional characters/being someone else (Sánchez-Bernardos \& Avia, 2004). The former supports evidence that paranormal believers are susceptible to distorted and false memories for ostensibly paranormal events (see French \& Stone, 2014) whereas the latter is consistent with evidence that believers engage in more avoidant coping (Callaghan \& Irwin, 2003; Rogers et al., 2006). Either way, it seems different facets of fantasy proneness (as 
measured by the CEQ) have different mediating strength on most aspects of adult paranormality and New Age orientation. Overall, H4 is supported.

Interestingly, it seems that a proneness to vivid/realistic and/or make-believe fantasizing are more important mediating factors in generating SUBs amongst sexual abuse survivors than for adults exposed to all other types of child maltreatment. This may reflect the perceived seriousness of child sexual assault and/or the tendency for many survivors to dissociate from their ordeal (e.g., Fergusson \& Mullen, 1999). Alternatively, it may simply be an artefact of the CATS sexual abuse subscale being dichotomized. More research is needed to confirm which interpretation is correct.

\subsection{Theoretical Implications}

The present study offers some support for Irwin's (2009) Psychodynamic Functions Hypothesis; the notion that adult paranormality is an adaptive, needs-serving mechanism for coping with a diminished sense of childhood control. First, it seems the PFH can be extended beyond anomalous beliefs and experiences to other aspects of adult SUB endorsement. Claiming to have a paranormal capabilities (e.g., actually being psychic), being less afraid of alleged paranormal activities (e.g., psychic readings, Ouija boards) and endorsing New Age concepts (e.g., karma, universal connectedness; Granqvist \& Hagekull, 2001) are ways by which adult survivors try to cope with the long-term psychological consequences of childhood maltreatment. Presumably this is achieved by engendering some illusion of control over people, objects and/or events even if only at an intellectual level (Irwin, 2009).

Second, the PFH can also be extended to include childhood neglect. In seems SUBs will, through engagement in vivid/realistic and/or make-believe fantasising, offer a means by which adults cope with the residual pain left over from feeling unwanted, unloved and unimportant as children (Sanders \& Becker-Lausen 1995). 
The PFH also extends to at least some one form of parentification although contrary to expectations it was those exposed to instrumental - not emotional - parentification who, though enhanced vivid/realistic and/or make-believe fantasizing, developed more pronounced SUBs in adulthood. A tentative interpretation is that adult paranormal and New Age worldviews provide a mechanism by which individuals learn to cope with a diminished sense of interpersonal freedom during childhood (Watt et al., 2007). In contrast, the lack of association with emotional parentification suggests more extreme child-parent role-reversal fails to engender a diminished sense of childhood control rendering the need for adaptive SUB-based coping unnecessary (cf. Irwin 2009). More work is needed to clarify and develop this line of reasoning.

Fourth, Irwin's PFH can also be extended to parental threats (rather than acts) of abuse. Individuals who were threatened with parental rejection report being less frightened of, and perhaps more prepared to utilise paranormal props (e.g., psychics, Ouija boards; Gallagher et al., 1994) in adulthood, presumably as a way of coping with the lack of domestic stability these threats generated (Lawrence et al., 1995; Watt et al., 2007).

Finally, a proneness to vivid/realistic and/or make-believe fantasizing renders adults who were maltreated as children more likely to endorse paranormal/New Age worldviews. Such fantasizing might manifest as believing in, experiencing and perhaps merging one's identity with fortune tellers (i.e. apparent telepathy) or spirit guides during demonstrations of mediumship (see Irwin \& Watt, 2007). By comparison, escapist fantasizing is not employed for this purpose presumably because prolonged daydreaming (Merckelbach et al, 2001) has little relevance to paranormal/New Age concepts. A second possibility is that vivid/realistic and make-believe fantasising tap into other concepts relevant to SUBs such as deficiencies in reality monitoring (cf. Irwin, 2009). More research is needed to explore these possibilities. 


\subsection{Methodological Issues \& Ideas for Future Research}

Given the complex nature of adult paranormality (Irwin, 2009) most models explained an impressive amount of criteria variance. Despite this, several methodological issues exist.

First, the low internal reliability of the CATS physical abuse subscale means current findings about its relationship with adult SUBs, which are at odds with previous trends (e.g., Perkins \& Allen, 2006), should be interpreted cautiously. Similarly, dichotomization of the CATS sexual abuse and all three PTI-R threat subscales weakens the "richness" and statistical power of these measures. Replication is needed.

Second, all childhood maltreatment predictors were necessarily retrospective and thus susceptible to memory distortions. Likewise, the current study suffers from potential bidirectionality in that adult SUBs may themselves influence recalled accounts of childhood maltreatment. In other words, believers' childhood memories could be biased because of their paranormal/New Age worldviews. Evidence that believers are susceptible to false memories and pro-paranormal confirmation biases (French \& Stone, 2014) support this assertion. Testing the PFH via longitudinal research would overcome such criticism.

Finally, childhood maltreatment was treated as if undertaken by both parents, a notion which seems unlikely. Future research ought to differentiate between maternal verses paternal maltreatment of children.

\section{General Conclusion}

Current findings suggest recalled experiences of child sexual abuse predict more frequent anomalous experiences in adulthood, with parental threats of rejection predictive of fewer anomalous fears. Additionally, childhood neglect, sexual abuse, emotional abuse and instrumental parentification all predict stronger paranormal and New Age worldviews through the mediating effects of heightened fantasy proneness; in particular more 
vivid/realistic and/or more make-believe fantasizing. Parallel claims cannot be made for other forms of child maltreatment such as physical abuse, emotional parentification and parental threats of abandonment or punishment. Overall, the present study offers partial support for Irwin's (2009) Psychodynamic Functions Hypothesis with the PFH now extended to include childhood neglect, self-proclaimed paranormal abilities, a lack of fear for alleged paranormal activity, a broader New Age spirituality and certain facets of fantasy proneness as relevant factors. More research is needed to verify these trends and establish more concretely which forms of childhood maltreatment are (in)direct predictors of adult paranormal and New Age worldviews. 


\section{Footnotes}

1. For current purposes the term "scientifically unaccepted beliefs" refers to an individual's paranormality (i.e. belief in, reported experiences of, claimed abilities for and/or fears of anomalous phenomena; cf. Gallagher, Kumar \& Pekula, 1994) plus New Age orientation (i.e. endorsement of non-theistic spirituality, Eastern philosophy, humanistic psychology, alternative medicine, esotericism and metaphysics; cf. Farias \& Granqvist, 2007).

2. Items within the CEQ's escapist subscale focus on daydreaming.

3. In all, two PQ items were deleted; one each from the fairness of parentification (i.e. "Members of my family understood me pretty well") and instrumental parentification (i.e. "Even though my parents meant well, I could not really depend on them to meet my needs") subscales.

4. Mean substitution was employed as this method of estimate missing data is relatively conservative. Skewed distributions were expected for most maltreatment measures so no outliers were removed.

5. Variable dichotomization was chosen over other forms of data transformation due to the former's ease of interpretation (Tabachnik \& Fidell, 2007) and was based on subscale ratings without means substitution.

6. For clarity demographic covariates are omitted from path diagrams. Tables presenting mediation statistics are available from the first author (PR).

7. Calculated as the product of the predictor-to-mediator coefficient ( $a$ path) multiplied by the mediator-to-criteria coefficient ( $b$ path). For details see Hayes (2013a). 


\section{References}

Berkowski, M., \& MacDonald, D. A. (2014). Childhood trauma and the development of paranormal beliefs. Journal of Nervous \& Mental Disease, 202(4), 305-312. doi:10.1097/NMD.0000000000000123.

Byng-Hall, J. (2008). The significance of children fulfilling parental roles: Implications for family therapy. Journal of Family Therapy, 30(2), 147-162. doi:10.1111/j.14676427.2008.00423.x.

Callaghan, A. \& Irwin, H., J. (2003). Paranormal belief as a psychological coping mechanism. Journal of the Society for Psychical Research, 67(872), 200-207. doi: unavailable.

Farias, M. \& Granqvist, P. (2007). The psychology of the New Age. In D. Kemp (Ed.). Handbook of New Age (pp. 123-150). Leiden, Netherlands: Brill.

Fergusson, D., M. \& Mullen, P., E. (1999). Childhood sexual abuse: an empirical based perspective. Sage: Thousand Oaks, CA.

French. C.C. \& Stone, A. (2014). Anomalistic psychology: Exploring paranormal belief and experience. London: Palgrave Macmillan.

Gallagher, C., Kumar, V., K. \& Pekula, R., J. (1994). The anomalous experiences inventory: reliability and validity. Journal of Parapsychology, 58(4), 402-428. doi: unavailable.

Granqvist, P., \& Hagekull, B. (2001). Seeking security in the New Age: On attachment and emotional compensation. Journal for the Scientific Study of Religion, 40(3), 529-547. doi:10.1111/0021-8294.00075.

Granqvist, P., Ivarsson, T., Broberg, A. G. \& Hagekull, B. (2007). Examining relations among attachment, religiosity, and new age spirituality using the adult attachment interview. Developmental Psychology, 43(5), 590-601. doi:10.1037/0012-1649.43.3.590. 
Hayes, A. F. (2013a). Introduction to mediation, moderation, and conditional process analysis: A regression-based approach. New York, NY, US: Guilford Press.

Hayes, A. (2013b). INDIRECT for SPSS (Software macro). Available online via http://www.afhayes.com/spss-sas-and-mplus-macros-and-code.html [Accessed 25 February 2015].

Hayes, A. (2013c). INDIRECT (Documentation). Available online via http://www.afhayes.com/public/indirect.pdf [Accessed 25 February 2015].

Hooper, L. M. (2007). Expanding the discussion regarding parentification and its varied outcomes: Implications for mental health research and practice. Journal of Mental Health Counseling, 29(2), 322-337. doi: unavailable.

Hooper, L. M., \& Wallace, S. A. (2009). Evaluating the parentification questionnaire: Psychometric properties and psychopathology correlates. Contemporary Family Therapy: An International Journal, 32(1), 52-68. doi:10.1007/s10591-009-9103-9.

Irwin, H. J. (1992). Origins and functions of paranormal belief: The role of childhood trauma and interpersonal control. Journal of the American Society for Psychical Research, 86(3), 199-208. doi: unavailable.

Irwin, H. J. (1994). Childhood trauma and the origins of paranormal belief: A constructive replication. Psychological Reports, 74(1), 107-111. doi:10.2466/pr0.1994.74.1.107.

Irwin, H. J. (2009). The psychology of paranormal belief: A researcher's handbook. Hatfield: University of Hertfordshire Press.

Irwin, H. J. \& Watt, C.A. (2007). An introduction to parapsychology (5th edition). Jefferson, NC: McFarland \& Co.

Kent, A., \& Waller, G. (1998). The impact of childhood emotional abuse: An extension of the Child Abuse and Trauma Scale. Child Abuse \& Neglect, 22(5), 393-399. doi:10.1016/S0145-2134(98)00007-6. 
Lawrence, T., Edwards, C., Barraclough, N., \& Church, S. (1995). Modelling childhood causes of paranormal belief and experience: Childhood trauma and childhood fantasy. Personality \& Individual Differences, 19(2), 209-215. doi:10.1016/0191-8869(95)000344.

Merckelbach, H., Horselenberg, R., \& Muris, P. (2001). The Creative Experiences Questionnaire (CEQ): A brief self-report measure of fantasy proneness. Personality \& Individual Differences, 31(6), 987-995. doi:10.1016/S0191-8869(00)00201-4.

Perkins, S., L. \& Allen, R. (2006). Childhood physical abuse and differential development of paranormal belief systems. Journal of Nervous \& Mental Diseases, 194(5), 349-355. doi: 10.1097/01.nmd.0000217832.85665.c5.

Rabeyron, T., \& Watt, C. (2010). Paranormal experiences, mental health and mental boundaries, and psi. Personality \& Individual Differences, 48(4), 487-492. doi:10.1016/j.paid.2009.11.029.

Rogers, P., Qualter, P., \& Phelps, G. (2007). The mediating \& moderating effects of loneliness and attachment style on belief in the paranormal. European Journal of Parapsychology, 22(2), 138-165. doi: unavailable.

Rogers P., Qualter P., Phelps, G. \& Gardner, K. (2006) Belief in the paranormal, coping and emotional intelligence. Personality \& Individual Differences, 41(6), 1089-1105. doi: 10.1016/j.paid.2006.04.014.

Ross, C. A., \& Joshi, S. (1992). Paranormal experiences in the general population. Journal of Nervous \& Mental Disease, 180(6), 357-361. doi:10.1097/00005053-199206000-00004.

Sánchez-Bernardos, M.L. \& Avia, M.D. (2004). Personality correlates of fantasy proneness among adolescents. Personality \& Individual Differences 37(5), 1069-1079. doi:10.1016/j.paid.2003.11.015. 
Scher, C. D., Stein, M. B., Ingram, R. E., Malcarne, V. L., \& McQuaid, J. R. (2002). The Parent Threat Inventory: Development, reliability, and validity. Child Abuse \& Neglect, 26(2), 207-225. doi:10.1016/S0145-2134(01)00317-9.

Tabacknick, B., G. \& Fidell, L.S. (2007). Using multivariate statistics (5th edition). Boston, MA: Pearson Education.

Tobacyk, J. J. (2004). A revised paranormal belief scale. International Journal of Transpersonal Studies, 23(23), 94-98. doi: unavailable.

Watt, C. A., Watson, S. \& Wilson, L. (2007). Cognitive and psychological mediators of anxiety: Evidence from a study of paranormal belief and perceived childhood control. Personality \& Individual Differences 42(2), 335-343. doi:10.1016/j.paid.2006.07.015. 
Table 1: Descriptive, Internal Reliability \& Normality Statistics: All Measures ${ }^{\dagger}$

\begin{tabular}{|c|c|c|c|c|c|c|c|}
\hline \multirow[b]{2}{*}{ Scale } & \multirow[b]{2}{*}{ Subscale } & \multirow[b]{2}{*}{$M$} & \multirow[b]{2}{*}{$(S D)$} & \multirow{2}{*}{$\begin{array}{c}\text { Chronbach's } \\
\text { Alpha }\end{array}$} & \multicolumn{3}{|c|}{ Normality } \\
\hline & & & & & $K-S$ & $p$ & \\
\hline \multirow[t]{4}{*}{ AEI } & anomalous experiences & 1.91 & $(.71)$ & .94 & 1.63 & .010 & $*$ \\
\hline & 2. anomalous beliefs & 2.51 & $(.86)$ & .89 & 0.80 & .547 & \\
\hline & 3. anomalous abilities & 1.69 & $(.63)$ & .90 & 2.25 & $<.001$ & $* * *$ \\
\hline & 4. anomalous fears & 2.14 & $(.80)$ & .76 & 1.24 & .091 & \\
\hline NAOS & new age orientation & 2.34 & $(.89)$ & .96 & 0.97 & .302 & \\
\hline \multirow[t]{3}{*}{ CEQ } & 1. vivid/realistic fantasies & 2.36 & $(.81)$ & .77 & 1.07 & .204 & \\
\hline & 2. escapist fantasizing ${ }^{\ddagger}$ & 2.43 & $(1.02)$ & .73 & 1.28 & .076 & \\
\hline & 3. make-believe fantasizing & 2.51 & $(.88)$ & .78 & 1.20 & .114 & \\
\hline \multirow[t]{4}{*}{ CATS } & 1. neglect & 2.04 & $(.92)$ & .93 & 2.08 & $<.001$ & $* * *$ \\
\hline & 2. sexual abuse & 1.30 & $(.59)$ & .79 & 5.19 & $<.001$ & $* * *$ \\
\hline & 3. physical abuse & 2.62 & $(.60)$ & .50 & 1.33 & .057 & $a$ \\
\hline & 4. emotional abuse & 2.23 & $(.95)$ & .91 & 1.79 & .003 & $* *$ \\
\hline \multirow[t]{3}{*}{ PTI-R } & 1. threat of rejection & 1.43 & $(.74)$ & .96 & 4.24 & $<.001$ & $* * *$ \\
\hline & 2. threat of abandonment & 1.68 & $(1.05)$ & .95 & 4.02 & $<.001$ & $* * *$ \\
\hline & 3. threat of punishment & 1.74 & $(.89)$ & .89 & 3.04 & $<.001$ & $* * *$ \\
\hline \multirow[t]{3}{*}{ PQ } & 1. fairness of parentification & 2.58 & $(.70)$ & .81 & 1.53 & .019 & $*$ \\
\hline & 2. emotional parentification & 2.02 & $(.88)$ & .87 & 1.88 & .002 & $* *$ \\
\hline & 3. instrumental parentification & 2.08 & $(.86)$ & .84 & 1.57 & .014 & $*$ \\
\hline
\end{tabular}

${ }^{\dagger}$ Child Abuse \& Trauma Scale (CATS); Parental Threat Inventory - Revised (PTI-R); Parentification Questionnaire (PQ); Creative Experiences Questionnaire (CEQ); Anomalous Experiences Inventory (AEI); New Age Orientation Scale (NAOS). All measures rated from 1-5 with higher scores indicating more abuse, threat, parentification, fantasy proneness, New Age orientation and anomalous worldviews. ${ }^{*}$ Final figures following item deletion. Sig. at the $\mathrm{p}<.05, * * \mathrm{p}<.01 * * * \mathrm{p}<.001$ levels; a=approaches significance (two-tailed; $n=226$ ). 
Table 2: Correlations ( $r$ ) with the Five Criteria (AIE \& NAOS) and Three Mediator (CEQ) Variables

\begin{tabular}{|c|c|c|c|c|c|c|c|c|c|c|c|c|c|c|c|c|c|}
\hline \multirow{3}{*}{$\begin{array}{l}\text { Scale } \\
\text { CEQ }\end{array}$} & \multirow{3}{*}{$\begin{array}{l}\text { Subscale } \\
\text { vivid/realistic fantasies }\end{array}$} & \multicolumn{10}{|c|}{ AIE \& NAOS } & \multicolumn{6}{|c|}{ CEQ } \\
\hline & & \multicolumn{2}{|c|}{$\begin{array}{l}\text { anomalous } \\
\text { experiences }\end{array}$} & \multicolumn{2}{|c|}{$\begin{array}{c}\text { anomalous } \\
\text { beliefs }\end{array}$} & \multicolumn{2}{|c|}{$\begin{array}{c}\text { anomalous } \\
\text { abilities }\end{array}$} & \multicolumn{2}{|c|}{$\begin{array}{c}\text { anomalous } \\
\text { fears }\end{array}$} & \multicolumn{2}{|c|}{$\begin{array}{l}\text { new age } \\
\text { orientation }\end{array}$} & \multicolumn{2}{|c|}{$\begin{array}{l}\text { vivid/realistic } \\
\text { fantasies }\end{array}$} & \multicolumn{2}{|c|}{$\begin{array}{l}\text { escapist } \\
\text { fantasies }\end{array}$} & \multicolumn{2}{|c|}{$\begin{array}{l}\text { make-believe } \\
\text { fantasies }\end{array}$} \\
\hline & & .40 & $* * *$ & 44 & $* * *$ & .40 & $* * *$ & .14 & * & .48 & $* * *$ & & & & & & \\
\hline & escapist fantasies & .26 & $* * *$ & .32 & $* * *$ & .25 & $* * *$ & .12 & $a$ & .37 & $* * *$ & .68 & $* * *$ & & & & \\
\hline & make-believe fantasies & .34 & $* * *$ & .42 & *** & .31 & *** & .17 & * & .43 & *** & .71 & *** & .55 & $* * *$ & & \\
\hline \multirow[t]{4}{*}{ CATS } & neglect & .12 & & .11 & & .06 & & -.01 & & .13 & $*$ & .23 & $* * *$ & .29 & $* * *$ & .24 & $* * *$ \\
\hline & sexual abuse $(\mathrm{Y} / \mathrm{N})^{\dagger}$ & .27 & $* * *$ & .14 & * & .20 & ** & .08 & & .14 & $*$ & .28 & $* * *$ & .30 & $* * *$ & .26 & $* * *$ \\
\hline & physical abuse & .08 & & -.01 & & .08 & & .01 & & .01 & & .05 & & .11 & & .06 & \\
\hline & emotional abuse & .13 & $a$ & .14 & * & .08 & & -.03 & & .11 & & .22 & ** & .30 & $* * *$ & .21 & ** \\
\hline \multirow[t]{3}{*}{ PTI-R } & threats of rejection $(\mathrm{Y} / \mathrm{N})^{\dagger}$ & .10 & & .06 & & .05 & & -.16 & $*$ & .04 & & .22 & $* *$ & .15 & * & .18 & ** \\
\hline & threats of abandonment $(\mathrm{Y} / \mathrm{N})^{t}$ & .04 & & .00 & & -.02 & & -.08 & & -.03 & & .21 & ** & .21 & $* *$ & .11 & \\
\hline & threats of punishment $(\mathrm{Y} / \mathrm{N})^{\dagger}$ & .12 & & .06 & & .10 & & -.04 & & .03 & & .15 & $*$ & .04 & & .12 & \\
\hline \multirow[t]{3}{*}{ PQ } & fairness of parentification & .12 & & .03 & & .07 & & -.01 & & .07 & & .18 & $* *$ & .19 & ** & .16 & * \\
\hline & emotional parentification & .11 & & .10 & & .08 & & .05 & & .12 & & .11 & & .11 & & .11 & \\
\hline & instrumental parentification & .07 & & .04 & & .06 & & .02 & & .13 & $*$ & .12 & & .09 & & .16 & $*$ \\
\hline \multirow[t]{5}{*}{ Demogs } & gender $^{\dagger}$ & .07 & & .06 & & .04 & & .16 & $*$ & .14 & * & .15 & * & -.04 & & .25 & $* * *$ \\
\hline & age & -.12 & & -.16 & $*$ & -.11 & & .06 & & -.09 & & -.23 & $* *$ & -.13 & $a$ & -.15 & * \\
\hline & ethnicity $^{\dagger}$ & .07 & & .07 & & -.02 & & .00 & & -.02 & & -.05 & & -.01 & & .04 & \\
\hline & occupation $^{\dagger}$ & .00 & & .06 & & .07 & & -.01 & & .05 & & .28 & $* * *$ & .16 & * & .19 & ** \\
\hline & qualifications & -.10 & & -.07 & & -.02 & & -.01 & & .00 & & .00 & & .00 & & -.10 & \\
\hline
\end{tabular}

$\dagger$ Dichotomised hence biserial $\left(r_{b}\right)$ or $p h i(\phi)$ coefficients; higher scores indicate female gender, Caucasian ethnicity, student occupational status \& some (vs. no) reported abuse/threat. Sig. at the * $<<05 * * \mathrm{p}<.01 * * *$ $\mathrm{p}<.001$ levels; $a=$ approaches sig. (two-tailed; $n=195$ to 226 ). 
Table 3: Indirect ( $a b)$ Path Coefficients and 95\% Confidence Intervals (CIs) following Mediation Analysis on Each Criteria Measure

\begin{tabular}{|c|c|c|c|c|c|c|c|c|c|c|c|c|c|c|c|c|c|c|c|c|c|}
\hline \multirow[t]{2}{*}{$\begin{array}{l}\text { Maltreatment } \\
\text { Predictor (IV) }\end{array}$} & \multirow[t]{2}{*}{$\begin{array}{l}\text { Fantasy Prone } \\
\text { Mediator (M) }\end{array}$} & \multicolumn{4}{|c|}{$\begin{array}{c}\text { Anomalous } \\
\text { Experiences }\end{array}$} & \multicolumn{4}{|c|}{$\begin{array}{c}\text { Anomalous } \\
\text { Beliefs }\end{array}$} & \multicolumn{4}{|c|}{$\begin{array}{c}\text { Anomalous } \\
\text { Abilities }\end{array}$} & \multicolumn{4}{|c|}{$\begin{array}{c}\text { Anomalous } \\
\text { Fears }\end{array}$} & \multicolumn{4}{|c|}{$\begin{array}{c}\text { New Age } \\
\text { Orientation }\end{array}$} \\
\hline & & $a b$ & Lwr & Upr & Sig. & $a b$ & Lwr & Upr & Sig. & $a b$ & Lwr & Upr & Sig. & $a b$ & Lwr & $\mathrm{Upr}$ & Sig. & $a b$ & Lwr & $\mathrm{Upr}$ & Sig. \\
\hline \multirow[t]{3}{*}{ neglect } & vivid fantasy & .06 & .01 & .13 & yes & .05 & .00 & .12 & yes & .06 & .02 & .12 & yes & -- & -- & -- & -- & .06 & .01 & .16 & yes \\
\hline & escapist fantasy & -.02 & -.08 & .02 & no & .00 & -.07 & .05 & no & -.01 & -.07 & .03 & no & -- & -- & -- & -- & .03 & -.02 & .10 & no \\
\hline & make-bel fantasy & .03 & -.01 & .09 & no & .07 & .02 & .15 & yes & .02 & -.02 & .07 & no & -- & -- & -- & -- & .05 & .01 & .12 & yes \\
\hline sexual & vivid fantasy & .14 & .03 & .28 & yes & .11 & .00 & .29 & no & .14 & .05 & .26 & yes & -- & -- & -- & -- & .15 & .04 & .34 & yes \\
\hline \multirow[t]{2}{*}{ abuse $(y / n)$} & escapist fantasy & -.04 & -.14 & .05 & no & -.30 & -.11 & .10 & no & -.03 & -.10 & .05 & no & -- & -- & -- & -- & .07 & -.05 & .20 & no \\
\hline & make-bel fantasy & .07 & -.03 & .19 & no & .17 & .07 & .36 & yes & .05 & -.03 & .17 & no & -- & -- & -- & -- & .11 & .02 & .25 & yes \\
\hline emotional & vivid fantasy & .05 & .01 & .13 & yes & .04 & .00 & .12 & yes & .05 & .02 & .12 & yes & -- & -- & -- & -- & .06 & .01 & .15 & yes \\
\hline \multirow[t]{2}{*}{ abuse } & escapist fantasy & -.02 & -.07 & .03 & no & .00 & -.06 & .06 & no & -.01 & -.07 & .03 & no & -- & -- & -- & -- & .03 & -.01 & .11 & no \\
\hline & make-bel fantasy & .02 & -.01 & .08 & no & .06 & .02 & .14 & yes & .02 & -.01 & .07 & no & -- & -- & -- & -- & .04 & .01 & .11 & yes \\
\hline \multirow{3}{*}{$\begin{array}{l}\text { insirumental } \\
\text { parentification }\end{array}$} & vivid fantasy & .04 & .00 & .11 & yes & .03 & .00 & .11 & no & .04 & .00 & .10 & yes & -- & -- & -- & -- & .04 & .00 & .13 & yes \\
\hline & escapist fantasy & -.01 & -.05 & .01 & no & .00 & -.04 & .02 & no & -.01 & -.04 & .01 & no & -- & -- & -- & -- & .01 & -.01 & .06 & no \\
\hline & make-bel fantasy & .02 & .00 & .09 & no & .06 & .01 & .16 & yes & .02 & -.01 & .08 & no & -- & -- & -- & -- & .04 & .00 & .11 & yes \\
\hline \multirow{3}{*}{$\begin{array}{l}\text { threat of } \\
\text { rejection }(\mathrm{y} / \mathrm{n})\end{array}$} & vivid fantasy & -- & -- & -- & -- & -- & -- & -- & -- & -- & -- & -- & -- & .03 & -.04 & .12 & no & -- & -- & -- & -- \\
\hline & escapist fantasy & -- & -- & -- & -- & -- & -- & -- & -- & -- & -- & -- & -- & .01 & -.03 & .08 & no & -- & -- & -- & -- \\
\hline & make-bel fantasy & -- & -- & -- & -- & -- & -- & -- & -- & -- & -- & -- & -- & .05 & .00 & .15 & no & -- & -- & -- & -- \\
\hline
\end{tabular}

Here, $a b$ coefficients reflect the indirect effect of IV on DV via M. CIs' bias corrected across 5000 bootstrapped samples. Significant indirect (mediation) effect if lower-to-upper $C I$ range does not include zero. 


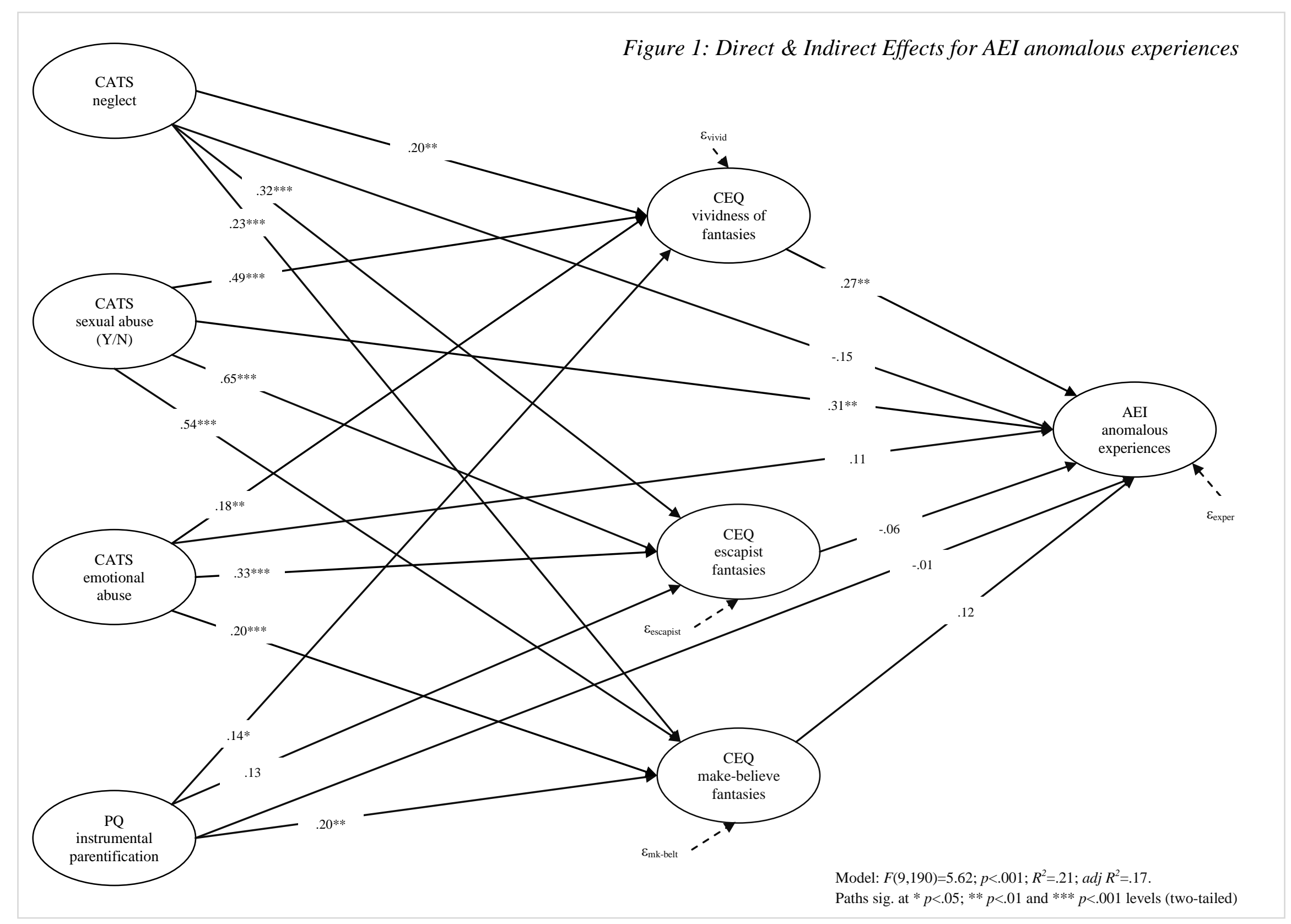




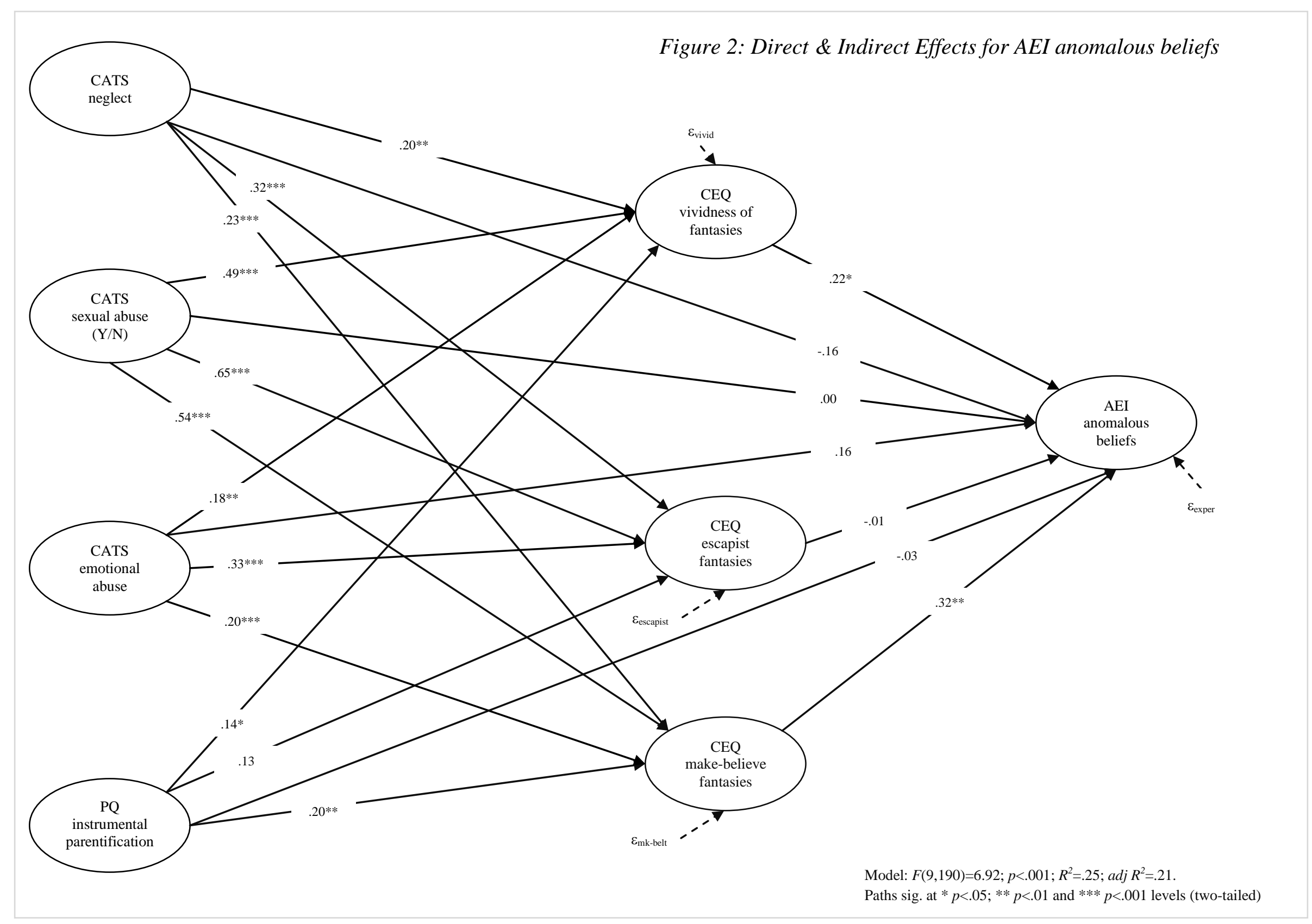




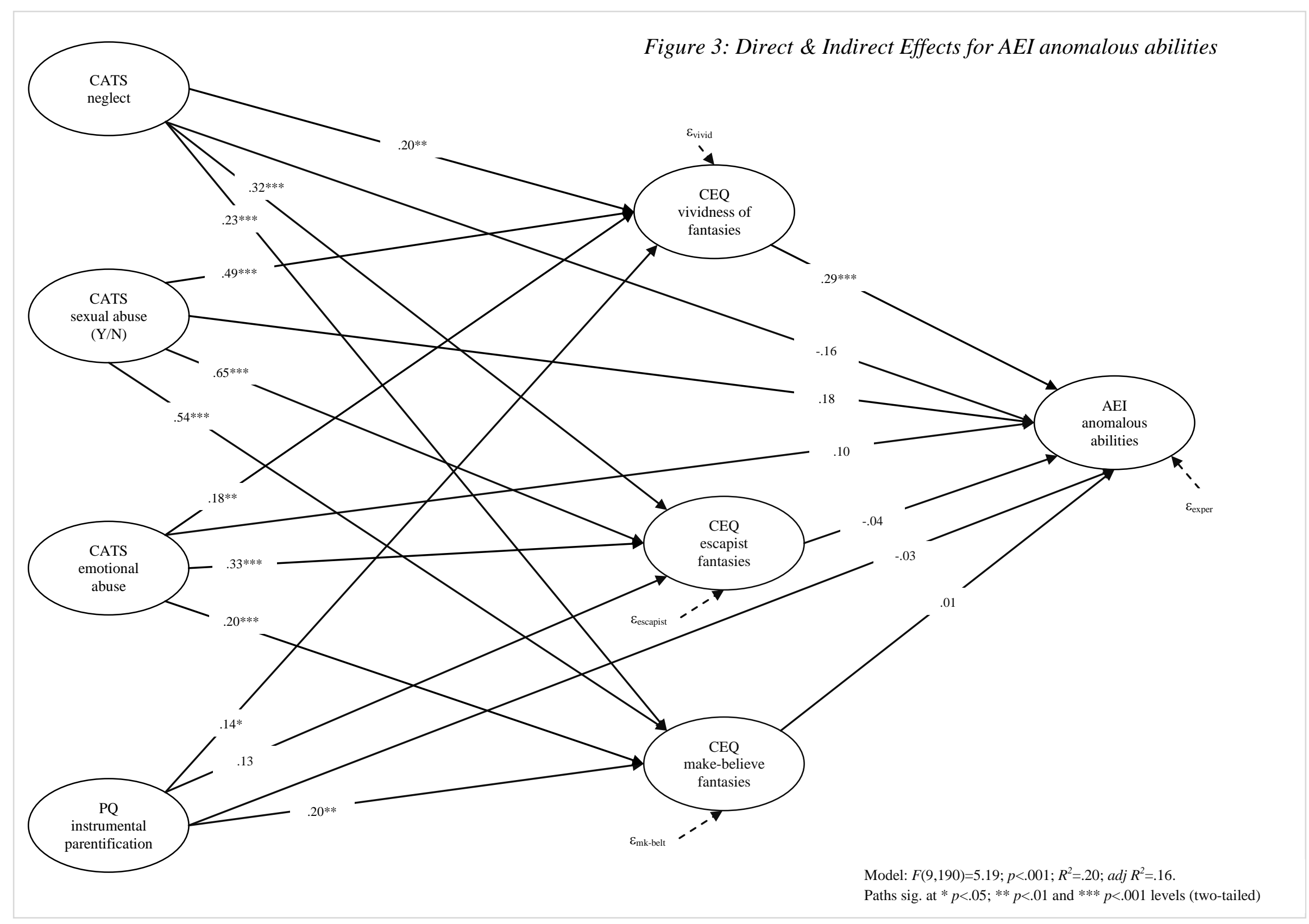




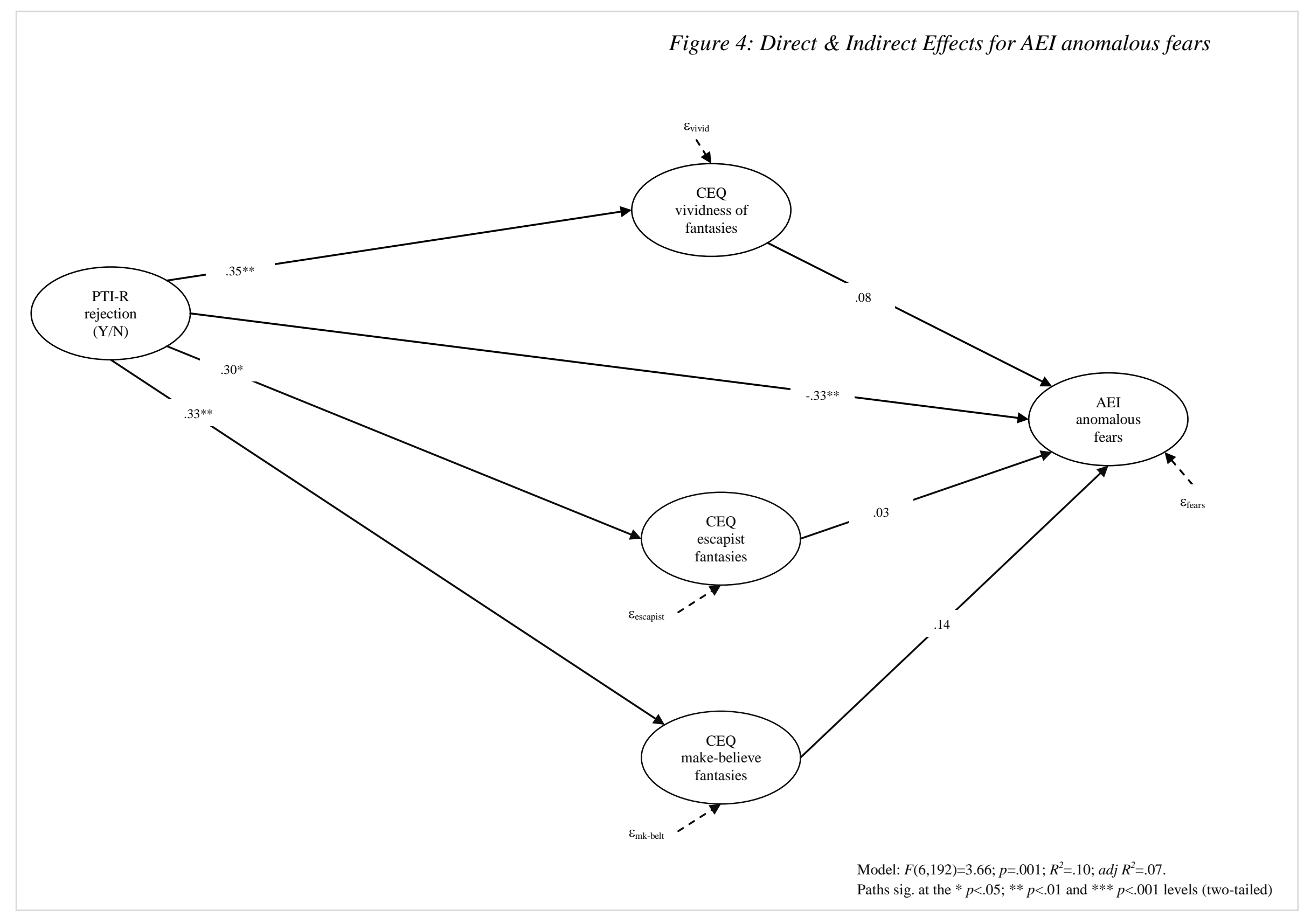




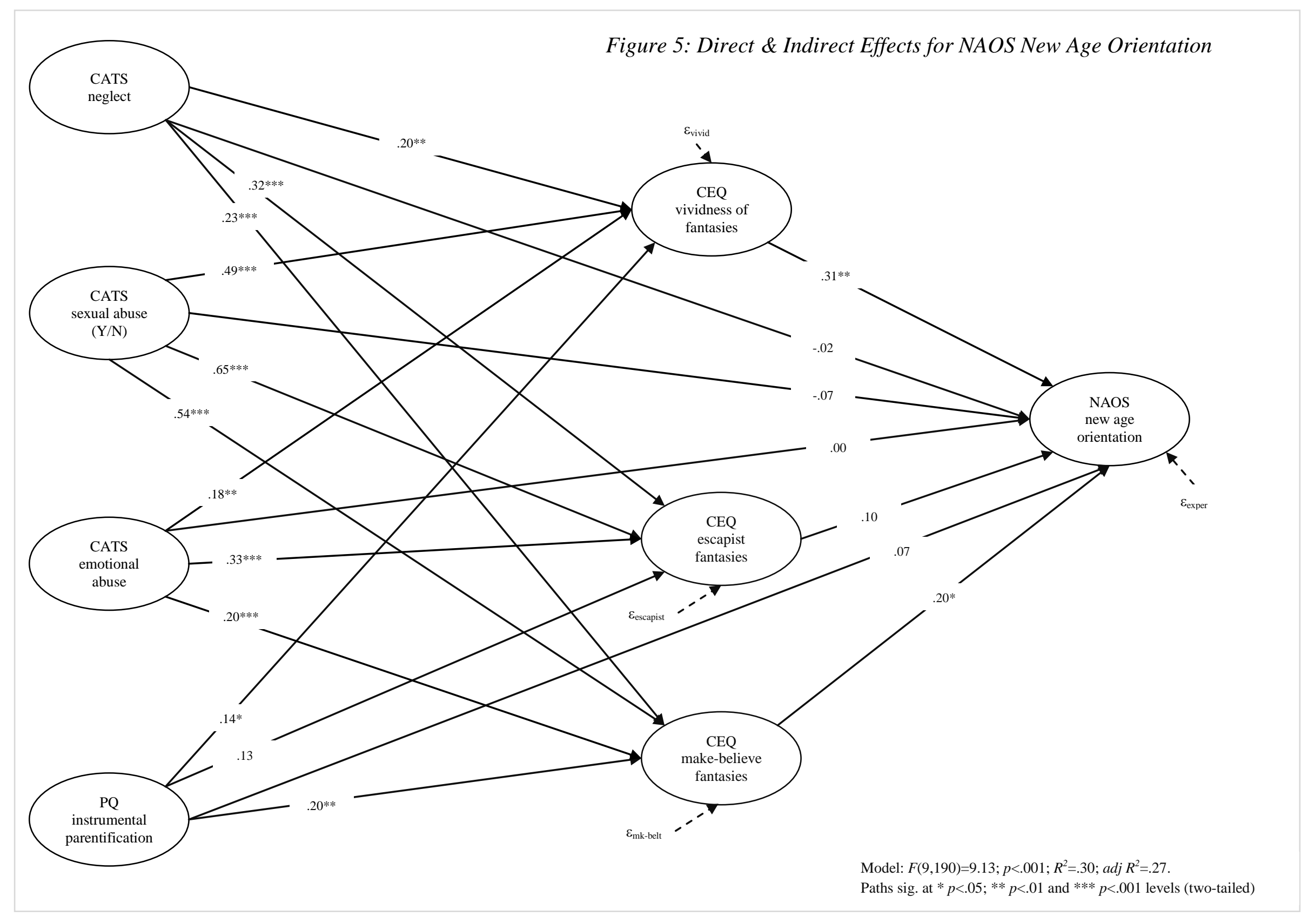




\section{Acknowledgements}

The authors would like to thank Professor Andrew Hayes, Dr Kris Preacher and Professor Zhonglin Wen for their statistical advice. Thanks also go to Kenneth Connelly and George White for their help with data collection and to three anonymous reviews for their useful comments. 
Table 4: Total, Direct \& Indirect Effects for AEI Anomalous Experiences ${ }^{\dagger}$

\begin{tabular}{|c|c|c|c|c|c|c|c|c|c|c|c|c|c|c|c|c|c|c|c|c|c|c|c|}
\hline \multirow[t]{3}{*}{$\begin{array}{l}\text { Predictor (IV) } \\
\end{array}$} & \multirow[t]{3}{*}{ Mediator (M) } & \multirow{2}{*}{\multicolumn{4}{|c|}{$\begin{array}{c}\text { Total Effect } \\
\text { IV on DV } \\
(c \text { path })\end{array}$}} & \multicolumn{12}{|c|}{ Direct Effects } & \multicolumn{6}{|c|}{ Indirect Effects } \\
\hline & & & & & & \multicolumn{4}{|c|}{$\begin{array}{c}\text { IV on M } \\
(a \text { path })\end{array}$} & \multicolumn{4}{|c|}{$\begin{array}{c}\text { M on DV } \\
(b \text { path })\end{array}$} & \multicolumn{4}{|c|}{$\begin{array}{l}\text { IV on DV } \\
\left.\text { ( } c^{\prime} \text { path }\right)\end{array}$} & \multicolumn{3}{|c|}{$\begin{array}{c}\text { IV on DV via M } \\
(a b \text { path })\end{array}$} & \multicolumn{3}{|c|}{$\begin{array}{l}\text { 95\% Confidence } \\
\text { Intervals }\end{array}$} \\
\hline & & $b$ & $(S E)$ & $p$ & & $b$ & $(S E)$ & $p$ & & $b$ & $(S E)$ & $p$ & & $b$ & $(S E)$ & $p$ & & Data & Boot & Bias & Lwr & Upr & Sig. \\
\hline \multirow[t]{4}{*}{ CATS neglect } & -- & .08 & .05 & .139 & & -- & -- & -- & & -- & -- & -- & & -.15 & .10 & .129 & & -- & -- & -- & -- & -- & -- \\
\hline & CEQ vividness & -- & -- & -- & & .20 & .06 & $<.001$ & *** & .27 & .09 & .004 & *** & -- & -- & -- & & .06 & .06 & .00 & .01 & .13 & yes \\
\hline & CEQ escapist & -- & -- & -- & & .32 & .07 & $<.001$ & *** & -.06 & .06 & .366 & & -- & -- & -- & & -.02 & -.02 & .00 & -.08 & .02 & no \\
\hline & CEQ make-bel & -- & -- & -- & & .23 & .06 & $<.001$ & $* * *$ & .12 & .08 & .133 & & -- & -- & -- & & .03 & .03 & .00 & -.01 & .09 & no \\
\hline \multirow{4}{*}{$\begin{array}{l}\text { CATS sexual } \\
(\mathrm{Y} / \mathrm{N})\end{array}$} & -- & .42 & .10 & .000 & $* * *$ & -- & -- & -- & & -- & -- & -- & & .31 & .12 & .007 & $* *$ & -- & -- & -- & -- & -- & -- \\
\hline & CEQ vividness & -- & -- & -- & & .49 & .12 & $<.001$ & $* * *$ & .27 & .09 & .004 & $* *$ & -- & - & - & & .14 & .14 & .01 & .03 & .28 & yes \\
\hline & CEQ escapist & -- & -- & -- & & .65 & .15 & $<.001$ & $* * *$ & -.06 & .06 & .366 & & -- & -- & -- & & -.04 & -.04 & .00 & -.14 & .05 & no \\
\hline & CEQ make-bel & -- & -- & -- & & .54 & .13 & $<.001$ & *** & .12 & .08 & .133 & & -- & -- & -- & & .07 & .06 & -.01 & -.03 & .19 & no \\
\hline \multirow[t]{4}{*}{ CATS emotion } & -- & .10 & .05 & .050 & $a$ & -- & -- & & & -- & -- & -- & & .11 & .09 & .233 & & -- & -- & -- & -- & -- & -- \\
\hline & CEQ vividness & -- & -- & -- & & .18 & .06 & .002 & ** & .27 & .09 & .004 & ** & -- & -- & -- & & .05 & .05 & .00 & .01 & .13 & yes \\
\hline & CEQ escapist & -- & -- & -- & & .33 & .07 & $<.001$ & $* * *$ & -.06 & .06 & .366 & & -- & -- & -- & & -.02 & $\begin{array}{ll}-.02 \\
-.02\end{array}$ & .00 & -.07 & .03 & no \\
\hline & CEQ make-bel & -- & -- & -- & & .20 & .06 & .002 & $* *$ & .12 & .08 & .133 & & -- & -- & -- & & .02 & .02 & .00 & -.01 & .08 & no \\
\hline \multirow[t]{4}{*}{$P Q$ instrument } & -- & .06 & .06 & .318 & & -- & -- & -- & & -- & -- & -- & & -.01 & .06 & .923 & & -- & -- & -- & - & -- & -- \\
\hline & CEQ vividness & -- & - & -- & & .14 & .07 & .040 & * & .27 & .09 & .004 & *** & -- & - & - & & .04 & .04 & .00 & .00 & .11 & yes \\
\hline & CEQ escapist & -- & -- & -- & & .13 & .08 & .127 & & -.06 & .06 & .366 & & -- & -- & -- & & -.01 & -.01 & .00 & -.05 & .01 & no \\
\hline & CEQ make-bel & -- & -- & -- & & .20 & .07 & .006 & ** & .12 & .08 & .133 & & -- & -- & -- & & .02 & .02 & .00 & .00 & .09 & no \\
\hline
\end{tabular}

$F(9,190)=5.62 ; p<.001 ; R^{2}=.21 ; \operatorname{adj} R 2=.17$

${ }^{\dagger}$ Data and Boot refer to indirect effects calculated on original data and means across 5000 bootstrapped samples respectively; Bias equals Boot minus Data. Controlling for respondent gender \& age. Confidence intervals (CIs) bias corrected. Beta Data and Boot refer to indirect effects calculated on original data and means across 5000 bootstrapped samples respectivel
coefficients to 2 decimal places. Sig. ${ }^{*} p<.05 ; * * *^{*}<.01$ and $* * * * x<.001$ levels; $a=$ approaches significance (two-tailed; $n=200$ ) 
Table 5: Total, Direct \& Indirect Effects for AEI Anomalous Beliefs ${ }^{\dagger}$

\begin{tabular}{|c|c|c|c|c|c|c|c|c|c|c|c|c|c|c|c|c|c|c|c|c|c|c|}
\hline \multirow[t]{3}{*}{ Predictor (IV) } & \multirow[t]{3}{*}{ Mediator (M) } & \multirow{2}{*}{\multicolumn{4}{|c|}{$\begin{array}{c}\text { Total Effect } \\
\text { IV on DV } \\
(c \text { path }) \\
\end{array}$}} & \multicolumn{11}{|c|}{ Direct Effects } & \multicolumn{6}{|c|}{ Indirect Effects } \\
\hline & & & & & & \multicolumn{4}{|c|}{$\begin{array}{c}\text { IV on M } \\
\text { ( } a \text { path })\end{array}$} & \multicolumn{4}{|c|}{$\begin{array}{c}\text { M on DV } \\
(b \text { path })\end{array}$} & \multicolumn{3}{|c|}{$\begin{array}{c}\text { IV on DV } \\
\text { (c' path) }\end{array}$} & \multicolumn{3}{|c|}{$\begin{array}{c}\text { IV on DV via M } \\
(a b \text { path })\end{array}$} & \multicolumn{3}{|c|}{$\begin{array}{l}\text { 95\% Confidence } \\
\text { Intervals }\end{array}$} \\
\hline & & $b$ & $(S E)$ & $p$ & & $b$ & $(S E)$ & $p$ & & $b$ & $(S E)$ & $p$ & & $b$ & $(S E)$ & $p$ & Data & Boot & Bias & Lwr & Upr & Sig. \\
\hline \multirow[t]{4}{*}{ CATS neglect } & -- & .09 & .07 & 162 & & -- & -- & -- & & -- & -- & -- & & -.16 & .12 & 182 & -- & -- & -- & -- & -- & -- \\
\hline & CEQ vividness & -- & -- & - & & .20 & .06 & $<.001$ & $* * *$ & .22 & .11 & 048 & * & - & -- & -- & .05 & .05 & .00 & .00 & .12 & yes \\
\hline & CEQ escapist & -- & -- & -- & & .32 & .07 & $<.001$ & $* * *$ & -.01 & .08 & 938 & & -- & -- & -- & .00 & .00 & .00 & -.07 & .05 & no \\
\hline & CEQ make-bel & -- & -- & -- & & .23 & .06 & $<.001$ & $* * *$ & .32 & .10 & .001 & $* *$ & -- & -- & -- & .07 & .07 & .00 & .02 & .15 & yes \\
\hline \multirow{4}{*}{$\begin{array}{l}\text { CATS sexual } \\
(\mathrm{Y} / \mathrm{N})\end{array}$} & -- & .26 & .13 & .049 & * & -- & -- & -- & & -- & -- & -- & & .00 & .14 & .983 & -- & -- & -- & -- & -- & -- \\
\hline & CEQ vividness & -- & -- & -- & & .49 & .12 & $<.001$ & **** & .22 & .11 & . 048 & * & -- & -- & -- & .11 & .11 & .00 & .00 & .29 & no \\
\hline & CEQ escapist & -- & -- & -- & & .65 & .15 & $<.001$ & $* * *$ & -.01 & .08 & .938 & & -- & -- & -- & -.30 & -.01 & .00 & -.11 & .10 & no \\
\hline & CEQ make-bel & -- & -- & -- & & .54 & .13 & $<.001$ & $* * *$ & .32 & .10 & .001 & $* *$ & -- & -- & -- & .17 & .17 & .00 & .07 & .36 & yes \\
\hline \multirow[t]{4}{*}{ CATS emotion } & -- & .13 & .06 & .045 & * & -- & -- & -- & & -- & -- & -- & & .16 & .11 & .142 & -- & -- & -- & -- & -- & - \\
\hline & CEQ vividness & -- & -- & - & & .18 & .06 & .002 & $* *$ & .22 & .11 & .048 & * & -- & -- & - & .04 & .04 & .00 & .00 & .12 & yes \\
\hline & CEQ escapist & -- & -- & -- & & .33 & .07 & $<.001$ & $* * *$ & -.01 & .08 & 938 & & -- & -- & -- & .00 & .00 & .00 & -.06 & .06 & no \\
\hline & CEQ make-bel & -- & -- & -- & & .20 & .06 & .002 & $* *$ & .32 & .10 & .001 & $* *$ & -- & -- & -- & .06 & .06 & .00 & .02 & .14 & yes \\
\hline \multirow[t]{4}{*}{$\mathrm{PQ}$ instrument } & -- & .06 & .07 & .433 & & - & -- & -- & & -- & -- & -- & & -.03 & .07 & .633 & -- & -- & -- & -- & -- & - \\
\hline & CEQ vividness & -- & -- & - & & .14 & .07 & .040 & * & .22 & .11 & .048 & * & - & -- & -- & .03 & .03 & .00 & .00 & .11 & no \\
\hline & CEQ escapist & -- & -- & -- & & .14 & .08 & .127 & & -.01 & .08 & .938 & & -- & -- & -- & .00 & .00 & .00 & -.04 & .02 & no \\
\hline & CEQ make-bel & -- & -- & -- & & .20 & .07 & .006 & $* *$ & .32 & .10 & .001 & $* *$ & -- & -- & -- & .06 & .06 & .00 & .01 & .16 & yes \\
\hline
\end{tabular}

${ }^{\dagger}$ Data and Boot refer to indirect effects calculated on original data and means across 5000 bootstrapped samples respectively; Bias equals Boot minus Data. Controlling for respondent gender \& age. Confidence intervals (CIs) bias corrected. Beta Data and Boot refer to indirect effects calculated on original data and means across 5000 bootstrapped samples respectively $;$
coefficients to 2 decimal places. Sig. * ${ }^{2}<.05 ; * * p<.01$ and $* * * p<.001$ levels; $a=$ approaches significance (two-tailed; $n=200$ ). 
Table 6: Total, Direct \& Indirect Effects for AEI Anomalous Abilities ${ }^{\dagger}$

\begin{tabular}{|c|c|c|c|c|c|c|c|c|c|c|c|c|c|c|c|c|c|c|c|c|c|c|}
\hline \multirow[t]{3}{*}{ Predictor (IV) } & \multirow[t]{3}{*}{ Mediator (M) } & \multirow{2}{*}{\multicolumn{4}{|c|}{$\begin{array}{c}\text { Total Effect } \\
\text { IV on DV } \\
(c \text { path })\end{array}$}} & \multicolumn{11}{|c|}{ Direct Effects } & \multicolumn{6}{|c|}{ Indirect Effects } \\
\hline & & & & & & \multicolumn{4}{|c|}{$\begin{array}{l}\text { IV on M } \\
(a \text { path })\end{array}$} & \multicolumn{4}{|c|}{$\begin{array}{c}\text { M on DV } \\
(b \text { path })\end{array}$} & \multicolumn{3}{|c|}{$\begin{array}{c}\text { IV on DV } \\
\text { (c' path) }\end{array}$} & \multicolumn{3}{|c|}{$\begin{array}{c}\mathrm{IV} \text { on DV via M } \\
(a b \text { path })\end{array}$} & \multicolumn{3}{|c|}{$\begin{array}{l}\text { 95\% Confidence } \\
\text { Intervals }\end{array}$} \\
\hline & & $b$ & $(S E)$ & $p$ & & $b$ & $(S E)$ & $p$ & & $b$ & $(S E)$ & $p$ & & $b$ & $(S E)$ & $p$ & Data & Boot & Bias & Lwr & Upr & Sig. \\
\hline \multirow[t]{4}{*}{ CATS neglect } & -- & .03 & .05 & .506 & & -- & -- & -- & & -- & -- & -- & & -.16 & .09 & .087 & -- & -- & -- & -- & -- & -- \\
\hline & CEQ vividness & -- & -- & -- & & .20 & .06 & $<.001$ & $* * *$ & .29 & .09 & $<.001$ & **** & -- & -- & -- & .06 & .06 & .00 & .02 & .12 & yes \\
\hline & CEQ escapist & -- & -- & -- & & .32 & .07 & $<.001$ & $* * *$ & -.04 & .06 & .458 & & -- & -- & -- & -.01 & -.01 & .00 & -.07 & .03 & no \\
\hline & CEQ make-bel & -- & -- & -- & & .23 & .06 & $<.001$ & $* * *$ & .09 & .07 & .231 & & -- & -- & -- & .02 & .02 & .00 & -.02 & .07 & no \\
\hline \multirow{4}{*}{$\begin{array}{l}\text { CATS sexual } \\
\text { (Y/N) }\end{array}$} & - & .26 & .10 & .007 & $* *$ & -- & - & -- & & -- & -- & -- & & .18 & .10 & .084 & -- & -- & -- & -- & -- & - \\
\hline & CEQ vividness & -- & -- & -- & & .49 & .12 & $<.001$ & $* * *$ & .29 & .09 & $<.001$ & $* * *$ & -- & -- & -- & .14 & .14 & .00 & .05 & .26 & yes \\
\hline & CEQ escapist & -- & -- & -- & & .65 & .15 & $<.001$ & $* * *$ & -.04 & .06 & .458 & & -- & -- & -- & -.03 & -.03 & .00 & -.10 & .05 & no \\
\hline & CEQ make-bel & -- & -- & -- & & .54 & .13 & $<.001$ & $* * *$ & .09 & .07 & .231 & & -- & -- & -- & .05 & .04 & .00 & -.03 & .17 & no \\
\hline \multirow{4}{*}{ CATS emotion } & -- & .06 & .05 & .208 & & -- & - & -- & & -- & -- & -- & & .10 & .08 & .256 & - & - & -- & -- & -- & - \\
\hline & CEQ vividness & -- & -- & -- & & .18 & .06 & .002 & $* *$ & .29 & .09 & $<.001$ & $* * *$ & -- & -- & -- & .05 & .05 & .00 & .02 & .12 & yes \\
\hline & CEQ escapist & -- & -- & -- & & .33 & .07 & $<.001$ & $* * *$ & -.04 & .06 & .458 & & -- & -- & -- & -.01 & -.01 & .00 & -.07 & .03 & no \\
\hline & CEQ make-bel & -- & -- & -- & & .20 & .06 & .002 & $* *$ & .09 & .07 & .231 & & -- & -- & -- & .02 & .02 & .00 & -.01 & .07 & no \\
\hline \multirow[t]{4}{*}{$\mathrm{PQ}$ instrument } & -- & .04 & .05 & .427 & & -- & - & - & & -- & -- & - & & .01 & .05 & .916 & - & - & -- & -- & -- & - \\
\hline & CEQ vividness & -- & -- & -- & & .14 & .07 & .040 & * & .29 & .09 & $<.001$ & $* * *$ & -- & -- & -- & .04 & .04 & .00 & .00 & .10 & yes \\
\hline & CEQ escapist & -- & -- & -- & & .14 & .08 & .127 & & -.04 & .06 & .458 & & -- & -- & -- & -.01 & -.01 & .00 & -.04 & .01 & no \\
\hline & CEQ make-bel & -- & -- & -- & & .20 & .07 & .006 & $* *$ & .09 & .07 & .231 & & -- & -- & -- & .02 & .02 & .00 & -.01 & .08 & no \\
\hline
\end{tabular}

$F(9,190)=5.19 ; p<.001 ; R^{2}=.20 ; \operatorname{adj} R^{2}=.16$

${ }^{\dagger}$ Data and Boot refer to indirect effects calculated on original data and means across 5000 bootstrapped samples respectively; Bias equals Boot minus Data. Controlling for respondent gender \& age. Confidence intervals (CIs) bias corrected. Beta Data and Boot refer to indirect effects calculated on original data and means across 5000 bootstrapped samples respectivel
coefficients to 2 decimal places. Sig. ${ }^{*} p<.05 ; * * *^{*}<.01$ and $* * * * x<.001$ levels; $a=$ approaches significance (two-tailed; $n=200$ ) 
Table 7: Total, Direct \& Indirect Effects for AEI Anomalous Fears ${ }^{\dagger}$

\begin{tabular}{|c|c|c|c|c|c|c|c|c|c|c|c|c|c|c|c|c|c|c|c|c|c|c|}
\hline \multirow[t]{3}{*}{ Predictor (IV) } & \multirow[t]{3}{*}{ Mediator (M) } & \multirow{2}{*}{\multicolumn{4}{|c|}{$\begin{array}{c}\text { Total Effect } \\
\text { IV on DV } \\
(c \text { path })\end{array}$}} & \multicolumn{11}{|c|}{ Direct Effects } & \multicolumn{6}{|c|}{$\begin{array}{l}\text { Indirect Effects } \\
\end{array}$} \\
\hline & & & & & & \multicolumn{4}{|c|}{$\begin{array}{l}\text { IV on M } \\
(a \text { path })\end{array}$} & \multicolumn{3}{|c|}{$\begin{array}{c}\text { M on DV } \\
(b \text { path })\end{array}$} & \multicolumn{4}{|c|}{$\begin{array}{c}\text { IV on DV } \\
\text { (c' path) }\end{array}$} & \multicolumn{3}{|c|}{$\begin{array}{l}\text { IV on DV via } \mathrm{M} \\
(a b \text { path })\end{array}$} & \multicolumn{3}{|c|}{$\begin{array}{l}95 \% \text { Confidence } \\
\text { Intervals }\end{array}$} \\
\hline & & $b$ & $(S E)$ & $p$ & & $b$ & $(S E)$ & $p$ & & $b$ & $(S E)$ & $p$ & $b$ & $(S E)$ & $p$ & & Data & Boot & Bias & Lwr & Upr & Sig. \\
\hline PTI-R rejection & -- & -.29 & .11 & .012 & $*$ & -- & -- & -- & & -- & -- & -- & -.33 & .11 & .004 & ** & -- & -- & -- & -- & -- & -- \\
\hline \multirow[t]{3}{*}{$(\mathrm{Y} / \mathrm{N})$} & CEQ vividness & -- & -- & -- & & .35 & .12 & .003 & ** & .08 & .11 & .497 & -- & -- & -- & & .03 & .03 & .00 & -.04 & .12 & no \\
\hline & CEQ escapist & -- & -- & -- & & .30 & .15 & .046 & * & .03 & .07 & .723 & -- & -- & -- & & .01 & .01 & .00 & -.03 & .08 & no \\
\hline & CEQ make-bel & -- & -- & -- & & .33 & .12 & .009 & $* *$ & .14 & .09 & .134 & -- & -- & -- & & .05 & .04 & .00 & .00 & .15 & no \\
\hline
\end{tabular}
${ }^{\dagger}$ Data and Boot refer to indirect effects calculated on original data and means across 5000 bootstrapped samples respectively; Bias equals Boot minus Data. Controlling for respondent gender \& age. Confidence intervals (CIs) bias corrected. Beta
coefficients to 2 decimal places. Sig. ${ }^{*} p<.05 ; * * p<.01$ and $* * * p<.001$ levels; $a=$ approaches significance (two-tailed; $\left.n=200\right)$. 
Table 8: Total, Direct \& Indirect Effects for NAOS New Age Orientation ${ }^{\dagger}$

\begin{tabular}{|c|c|c|c|c|c|c|c|c|c|c|c|c|c|c|c|c|c|c|c|c|c|c|}
\hline \multirow[t]{3}{*}{ Predictor (IV) } & \multirow[t]{3}{*}{ Mediator (M) } & \multirow{2}{*}{\multicolumn{4}{|c|}{$\begin{array}{c}\text { Total Effect } \\
\text { IV on DV } \\
(c \text { path })\end{array}$}} & \multicolumn{11}{|c|}{ Direct Effects } & \multicolumn{6}{|c|}{ Indirect Effects } \\
\hline & & & & & & \multicolumn{4}{|c|}{$\begin{array}{l}\text { IV on M } \\
(a \text { path })\end{array}$} & \multicolumn{4}{|c|}{$\begin{array}{c}\text { M on DV } \\
(b \text { path })\end{array}$} & \multicolumn{3}{|c|}{$\begin{array}{c}\text { IV on DV } \\
\left(c^{\prime} \text { path }\right)\end{array}$} & \multicolumn{3}{|c|}{$\begin{array}{c}\text { IV on DV via M } \\
(a b \text { path })\end{array}$} & \multicolumn{3}{|c|}{$\begin{array}{l}\text { 95\% Confidence } \\
\text { Intervals }\end{array}$} \\
\hline & & $b$ & $(S E)$ & $p$ & & $b$ & $(S E)$ & $p$ & & $b$ & $(S E)$ & $p$ & & $b$ & $(S E)$ & $p$ & Data & Boot & Bias & Lwr & Upr & Sig. \\
\hline \multirow[t]{4}{*}{ CATS neglect } & -- & .13 & .07 & .053 & $a$ & -- & -- & -- & & -- & -- & -- & & -.02 & .12 & .844 & -- & -- & -- & -- & -- & -- \\
\hline & CEQ vividness & -- & -- & -- & & .20 & .06 & $<.001$ & **** & .31 & .11 & .004 & *** & -- & -- & -- & .06 & .07 & .00 & .01 & .16 & yes \\
\hline & CEQ escapist & -- & -- & -- & & .32 & .07 & $<.001$ & $* * *$ & .10 & .07 & .175 & & -- & -- & -- & .03 & .03 & .00 & -.02 & .10 & no \\
\hline & CEQ make-bel & -- & -- & -- & & .23 & .06 & $<.001$ & $* * *$ & .20 & .09 & .032 & * & -- & -- & -- & .05 & .05 & .00 & .01 & .12 & yes \\
\hline \multirow{4}{*}{$\begin{array}{l}\text { CATS sexual } \\
(\mathrm{Y} / \mathrm{N})\end{array}$} & -- & .27 & .13 & .045 & * & -- & -- & -- & & -- & -- & -- & & -.07 & .13 & .614 & -- & -- & -- & -- & -- & - \\
\hline & CEQ vividness & -- & -- & -- & & .49 & .12 & $<.001$ & **** & .31 & .11 & .004 & *** & -- & -- & -- & .15 & .16 & .00 & .04 & .34 & yes \\
\hline & CEQ escapist & -- & -- & -- & & .65 & .15 & $<.001$ & $* * *$ & .10 & .07 & .175 & & -- & -- & -- & .07 & .06 & .00 & -.05 & .20 & no \\
\hline & CEQ make-bel & -- & -- & -- & & .54 & .13 & $<.001$ & $* * *$ & .20 & .09 & .032 & $*$ & -- & -- & -- & .11 & .11 & .00 & .02 & .25 & yes \\
\hline \multirow{4}{*}{ CATS emotion } & -- & .12 & .06 & .066 & $a$ & -- & - & -- & & -- & -- & - & & .00 & .11 & .986 & - & -- & -- & -- & -- & - \\
\hline & CEQ vividness & -- & -- & -- & & .18 & .06 & .002 & ** & .31 & .11 & .004 & ** & -- & -- & -- & .06 & .06 & .00 & .01 & .15 & yes \\
\hline & CEQ escapist & -- & -- & -- & & .33 & .07 & $<.001$ & $* * *$ & .10 & .07 & .175 & & -- & -- & -- & .03 & .03 & .00 & -.01 & .11 & no \\
\hline & CEQ make-bel & -- & -- & -- & & .20 & .06 & .002 & $* *$ & .20 & .09 & .032 & * & -- & -- & -- & .04 & .04 & .00 & .01 & .11 & yes \\
\hline \multirow[t]{4}{*}{$\mathrm{PQ}$ instrument } & -- & .15 & .07 & .035 & * & - & -- & -- & & -- & - & - & & .07 & .07 & .290 & - & -- & -- & -- & -- & - \\
\hline & CEQ vividness & -- & -- & -- & & .14 & .07 & . 040 & * & .31 & .11 & .004 & *** & -- & -- & -- & .04 & .04 & .00 & .00 & .13 & yes \\
\hline & CEQ escapist & -- & -- & -- & & .14 & .08 & .127 & & .10 & .07 & .175 & & -- & -- & -- & .01 & .01 & .00 & -.01 & .06 & no \\
\hline & CEQ make-bel & -- & -- & -- & & .20 & .07 & .006 & $* *$ & .20 & .09 & .032 & * & -- & -- & -- & .04 & .04 & .00 & .00 & .11 & yes \\
\hline
\end{tabular}

$F(9,190)=9.13 ; p<.001 ; R^{2}=.30 ; \operatorname{adj} R^{2}=.27$

${ }^{\dagger}$ Data and Boot refer to indirect effects calculated on original data and means across 5000 bootstrapped samples respectively; Bias equals Boot minus Data. Controlling for respondent gender \& age. Confidence intervals (CIs) bias corrected. Beta Data and Boot refer to indirect effects calculated on original data and means across 5000 bootstrapped samples respectivel
coefficients to 2 decimal places. Sig. ${ }^{*} p<.05 ; * * *^{*}<.01$ and $* * * * x<.001$ levels; $a=$ approaches significance (two-tailed; $n=200$ ) 